\title{
Ericoid mycorrhizal symbiosis: theoretical background and methods for its comprehensive investigation
}

\author{
Martin Vohník ${ }^{1}$
}

Received: 10 May 2020 / Accepted: 14 September 2020 / Published online: 12 October 2020

c) Springer-Verlag GmbH Germany, part of Springer Nature 2020

\begin{abstract}
Despite decades of intensive research (especially from 1970s to 1990s), the ericoid mycorrhizal (ErM) hair root is still largely terra incognita and this simplified guide is intended to revive and promote the study of its mycobiota. Basic theoretical knowledge on the ErM symbiosis is summarized, followed by practical advices on Ericaceae root sample collection and handling, microscopic observations and photo-documentation of root fungal colonization, mycobiont isolation, maintenance and identification and resynthesis experiments with ericoid plants. The necessity of a proper selection of the root material and its surface sterilization prior to mycobiont isolation is stressed, together with the need of including suitable control treatments in inoculation experiments. The culture-dependent approach employing plating of single short $(\sim 2 \mathrm{~mm})$ hair root segments on nutrient media is substantiated as a useful tool for characterization of Ericaceae root-associated fungal communities; it targets living mycelium and provides metabolically active cultures that can be used in physiological experiments and taxonomic studies, thus providing essential reference material for culture-independent approaches. On the other hand, it is stressed that not every mycobiont isolated from an ericoid hair root necessarily represent an ErM fungus. Likewise, not every intracellular hyphal coil formed in the Ericaceae rhizodermis necessarily represents the ErM symbiosis. Taxonomy of the most important ericoid mycobionts is updated, mutualism in the ErM symbiosis is briefly discussed from the mycobiont perspective, and some interesting lines of possible future research are highlighted.
\end{abstract}

Keywords Culture-dependent approach $\cdot$ Ericaceae $\cdot$ Ericoid mycorrhizal fungal diversity $\cdot$ In vitro resynthesis $\cdot$ Isolate identification $\cdot$ Microscopy $\cdot$ Mycobiont isolation $\cdot$ Plating of surface-sterilized root segments

\section{Introduction}

Ericoid mycorrhiza is arguably the least researched and perhaps also the least understood type of mycorrhizal symbiosis. During past 3 years (2017-2019), Mycorrhiza had received only nine manuscripts focused on this intriguing type of root-fungus association (four short notes including one re-submission and five original articles) and two thirds of them had to be declined. In other words, only three manuscripts were eventually accepted for publication, including only one original article. These are frustrating numbers, especially because a half of the rejected manuscripts came from underresearched regions (snowmelt

Martin Vohník

vohnik@ibot.cas.cz

1 Department of Mycorrhizal Symbioses, Institute of Botany, Czech Academy of Sciences, Průhonice 252 43, Czech Republic sites in Japan, fynbos sites in South Africa, sand dune sites in southern Brazil) and their informative potential was unnecessarily wasted (at the time of writing, they do not appear in any other IF journal). Hence, the main rationale of this review is to help interested beginners through summarizing basic knowledge on the ericoid mycorrhizal (ErM) symbiosis and describing basic methodology used in the "traditional" ErM research, in hopes of preventing the most common shortcomings compromising their investigations.

\section{To isolate or not to isolate}

The "traditional" methodology combines microscopic and culture-dependent (i.e., isolation of root mycobionts into pure culture followed by their molecular identification and in vitro resynthesis) approaches, while the "modern" methodology relies on culture-independent approaches 
(i.e., isolation of total DNA + amplification of selected fungal gene(s) followed by their cloning and Sanger sequencing or high-throughput sequencing (HTS)). The main advantages of the traditional methodology are obvious: it is less demanding in terms of laboratory equipment, resources and bioinformatics and while the culture-independent approaches detect fungal DNA (also from moribund fungal structures) and all the connected science is performed in silico, the culture-dependent approach focuses on living mycelium and provides metabolically active cultures for further investigations. The main disadvantage is also obvious: it can only target cultivable mycobionts (the cultivation bias, also see Ritz 2007). On the other hand, also the culture-independent approaches are biased (e.g., the PCR/primer bias, also see Nichols et al. 2018), many mycobionts traditionally regarded as difficult-to-cultivate/non-cultivable may be in fact relatively easy to isolate and maintain in longterm culture when focusing on appropriate plant material and using appropriate techniques and nutrient media (see Vohník et al. 2016a, cf. Donachie et al. 2007), and cultures are necessary to clarify the species symbiotic status through in vitro resynthesis and to describe new species with deposited holotypes (Agerer et al. 2000, also see Seifert 2017 and Zamora et al. 2018).

In contrast to other main mycorrhizal types, the global diversity of ErM fungi (ErMF) is a great unknown and while isolation of mycobionts for estimation of diversity typically makes little sense for arbuscular mycorrhizal (AM) and ectomycorrhizal (EcM) fungi (AMF and EcMF, respectively), it still remains a useful tool in the ErM research. "There are good reasons for isolating endophytic microorganisms" (Hallmann et al. 2006), and this applies also to the Ericaceae root mycobionts: many cultivable ErMF lineages are probably still unknown/remain unnamed, and the great majority of those already known/named are insufficiently characterized both in terms of physiology and interactions with the host plants. An illustrative example of the importance of the traditional methodology is the discovery of sheathed ericoid mycorrhiza, impossible without a combination of advanced microscopy and targeted isolation of the basidiomycetous mycobiont coupled with resynthesis and physiological experiments (Vohník et al. 2012a), followed by a multi-gene molecular identification of the mycobiont (Kolařík and Vohník 2018). In contrast, the currently used HTS methods focusing on the nuc-rDNA (especially the internal transcribed spacer (ITS) region, i.e., the primary fungal barcode marker (Schoch et al. 2012)) do not detect the mycobiont, which necessarily leads to an underestimation of the actual occurrence of sheathed ericoid mycorrhiza in nature. That said, both approaches are complementary and ideally should be combined as they may provide very different views of the same root microbial community (e.g., Allen et al. 2003, Donachie et al. 2007 and Walker et al. 2011, but see Vohník et al. 2017).

\section{Theoretical background}

Alongside flawed methodology, declined manuscripts often contain wrong terminology, confusing statements about the ErM symbiosis and ErMF as well as outdated fungal taxonomy. Hence, the main aim of this section is to introduce/explain basic terms used in the ErM research and update some ErMF taxon names. In addition, some lines of possible future research are indicated. For explanation of basic mycorrhizal terminology, see Brundrett et al. (1996); for structural aspects of ericoid mycorrhiza, see Chap. 4 in Peterson et al. (2004) and Massicotte et al. (2005); for general introduction to the ErM symbiosis, including historical background and physiological experiments, see Read and Kerley (1999) and Smith and Read (2008a); and for the ErM symbiosis functioning at the ecosystem level, see Cairney and Meharg (2003), Read et al. (2004), and Smith and Read (2008b).

1 Ericaceae (Ericales, eight/nine subfamilies depending on the status of Pyroloideae, see Kron and Luteyn 2005 and Freudenstein et al. 2016) are an obligate mycorrhizal family, i.e., it is supposed that their ecological and evolutionary success is in a significant part due to specific root symbioses with soil fungi (Read 1983). Members of the early anther inversion clade (=core Ericaceae, Ericaceae s. str., as ericoid plants, species etc. in the following text; five subfamilies, see Kron et al. 2002 and Freudenstein et al. 2016) form a characteristic mutualistic (but see the section "Conclusions-what it takes to assign a mycobiont as "ericoid mycorrhizal"?") root-fungus association that is called the ErM symbiosis (coined by Harley 1959). In reality, however, just a handful of ericoid genera were thoroughly screened for ErM colonization and especially ErMF diversity and research on members of Cassiopoideae, Harrimanelloideae, and Styphelioideae (the latter formerly as the Southern Hemisphere's ErM family Epacridaceae, see Cairney and Ashford (2002)), but also several neglected tribes of Ericoideae and Vaccinioideae, is encouraged.

2 Ericoid mycorrhiza is a structurally well-defined endomycorrhizal type easily distinguishable from other types of mycorrhizae based on the fine compact intracellular hyphal coils formed in the rhizodermal cells of healthy ericoid hair roots (Read 1996, also see Figs. 9-12 in Steinke et al. 1996). Hyphal mantles/ sheaths on the hair root surface, in a way similar to those occurring in certain types of ectomycorrhizae, may be 
sometimes present (Rains et al. 2003; Massicotte et al. 2005; Vohník et al. 2012a). Both single-cell (i.e., from soil to individual rhizodermal cells) and cell-to-cell (i.e., between neighboring rhizodermal cells) hyphal colonization may occur in the rhizodermis of the ErM hair roots (Massicotte et al. 2005). A symbiosis morphologically very similar to identical to ericoid mycorrhiza, formed by mycobionts phylogenetically related to ErMF, has been reported in the fine lateral roots of Schizocodon soldanelloides var. magnus (Diapensiaceae, Ericales) (Okuda et al. 2011). Members of Enkianthoideae, the basal subfamily of Ericaceae, typically form the AM symbiosis. However, Obase et al. (2013) observed frequent "fine intracellular hyphal coils" in Enkianthus spp. roots and these morphologically correspond to the ErM hyphal coils (see Fig. 3c in that paper). Moreover, the cultivable root mycobiont spectra of Enkianthus campanulatus reported by Obase and Matsuda (2014) comprised many helotialean species with affinities to known ErMF, including members of the Hyaloscypha hepaticicola aggregate and Oidiodendron (see below). The possibility that Diapensiaceae and Enkianthoideae form the ErM symbiosis is intriguing and begs further investigation.

3 Besides the ErM symbiosis, ericoid plants may form different types of ectendomycorrhizae (Rains et al. 2003; Setaro et al. 2006; Vohník and Albrechtová 2011). Some authors have reported the presence of AM (e.g., Gemma and Koske 1990; Koske et al. 1990; Dighton and Coleman 1992; Urcelay 2002) and EcM (e.g., Largent et al. 1980; Kohn and Stasovski 1990; Dighton and Coleman 1992; Smith et al. 1995; Fujimura and Egger 2012) symbioses in the roots of ericoid plants, but ecophysiological significance of these observations remains unknown (also see the section "Root sample collection and handling" and item 3 under "Things to consider" in the section "Microscopic observations and photo-documentation") and further research on this topic is needed and encouraged.

4 ErMF are true mycorrhizal fungi (but see the section "Conclusions-what it takes to assign a mycobiont as "ericoid mycorrhizal"?"), not fungal root endophytes (for a reasonable delimitation of the term "endophyte" see Wilson 1995, also see Schulz and Boyle 2005 and references therein), and in general, they are distinct from the mycobionts forming other types of mycorrhizae. Possible exceptions comprise the ascomycetous EcMF Hyaloscypha bicolor (syn. Meliniomyces bicolor) and Hyaloscypha finlandica (syn. Cadophora finlandica) (Vrålstad 2004). However, the supportive in vitro resynthesis experiments (Monreal et al. 1999; Villarreal-Ruiz et al. 2004; Grelet et al. 2009; Vohník et al. 2013) are of only limited ecophysiological significance, mainly because it seems (at least so far) that these fungi typically do not occur in ericoid roots (to my knowledge only two reports are available on their isolation, see Vrålstad et al. 2002 and Bruzone et al. 2017, also see the inhibition of Piceirhiza bicolorata by ericoid plants in Kohout et al. 2011) and because the inoculated isolates were actually not obtained from ericoid roots (cf. Koch's postulatesfor a detailed background, explanation, and current views on the postulates see https://en.wikipedia.org/ wiki/Koch\%27s_postulates). Further research into the relevance of $H$. bicolor and $H$. finlandica as ErMF is needed and encouraged.

5 The currently recognized true ErMF (based on isolations from ericoid roots and successful in vitro resynthesis experiments) belong both to Ascomycota and Basidiomycota. The ascomycetous ErMF comprise $H$. hepaticicola (see below) and possibly also Hyaloscypha variabilis (syn. Meliniomyces variabilis, formerly known as Variable White Taxon, see Hambleton and Sigler 2005) from the $H$. hepaticicola aggregate, Oidiodendon maius (Myxotrichaceae, see Rice and Currah 2006), and Leohumicola spp. (Leotiomycetes, see Grunewaldt-Stöcker et al. 2013, also see Baba and Hirose 2020). The basidiomycetous ErMF comprise mycobionts from Serendipitaceae (Sebacinales, Vohník et al. 2016a) and a member of the Kurtia argillacea species complex (syn. Hyphoderma argillaceum, Hyphodontia argillaceum, Hymenochaetales) forming sheathed ericoid mycorrhiza (Kolařík and Vohník 2018). That said, most of our knowledge on the ErMF diversity comes from the temperate and boreal ecosystems of the Northern Hemisphere and the real number of true ErMF is undoubtedly higher-for example, two new ascomycetous genera most probably representing ErMF (i.e., Cairneyella (Midgley et al. 2016) and Gamarada (Midgley et al. 2018)) have been recently described from Australian Styphelioideae. Research on the diversity and identity of mycobionts associated with ericoid roots especially outside the already explored areas (see Fig. 22.2 in Grelet et al. 2016) coupled with experimental verification of their symbiotic status is encouraged.

6 Hyaloscypha hepaticicola remains the only ErMF in compliance with Koch's postulates for which the bi-directional nutrient transfer characteristic for most mycorrhizal types has been demonstrated (Pearson and Read 1973a). Despite that some authors reported its absence in the investigated ericoid roots (see Bruzone et al. 2015 and references therein), $H$. hepaticicola seems to have a cosmopolitan distribution (Bruzone et al. 2017; Midgley et al. 2017). However, the factors 
influencing its distribution/occurrence in ericoid roots are unknown and their investigation is encouraged.

7 Hyaloscypha hepaticicola has a remarkably turbulent history of taxonomic treatments and its synonyms include (chronologically) Pezizella ericae, Hymenoscyphus ericae, Scytalidium vaccinii, Rhizoscyphus ericae, and Pezoloma ericae, S. vaccinii representing its asexual state (= anamorph, see Egger and Sigler 1993). It belongs to a guild of closely related root-symbiotic and saprobic (i.e., non-symbiotic) fungi that bears its name, i.e., the $H$. hepaticicola aggregate (=Hyaloscypha s. str., see Fehrer et al. 2019), formerly known as the Hymenoscyphus ericae aggregate (coined by Vrålstad et al. 2000) and the Rhizoscyphus ericae aggregate. The aggregate contains several potentially important yet undescribed root-symbiotic lineages, and their species-level taxonomic treatment is needed. Using updated taxonomy is important, e.g., because the mycobiont's genus/family assignment is often used for extrapolation of its lifestyle-while Pezizella (typified by $P$. sordida) belongs to Thelebolaceae, Hymenoscyphus (H. fructigenus), Rhizoscyphus (now monotypic with $R$. monotropae) and Scytalidium ( $S$. lignicola) to Helotiaceae, and Pezoloma (P. griseum) to Leotiaceae (MycoBank, https://www.mycobank.org, accessed 6 October 2020), the actual placement of the prominent ErMF is in Hyaloscypha/Hyaloscyphaceae (Fehrer et al. 2019).

8 The great majority of our knowledge on functioning of the ErM symbiosis is based on many experiments with a few isolates of a single ascomycetous species (i.e., H. hepaticicola) and falls under the "HymenoscyphusCalluna/Vaccinium/Rhododendron model" (Straker 1996). This sharply contrasts with the surprisingly high diversity of mycobionts associated with ericoid roots and the many diverse ecosystem types ericoid plants actually inhabit (see Fig. 1 in Kron and Luteyn 2005). Investigations into functional aspects of other mycobionts associating with ericoid roots (cf. papers on O. maius and the Australian ErMF Gamarada debralockiae) are needed and encouraged.

9 There are many reports claiming other mycobionts as ErMF (e.g., Acremonium, Capronia, Clavaria, Cryptosporiopsis, Geomyces and Lachnum spp., also see Straker 1996, Monreal et al. 1999 and Read and Kerley 1999), but these need targeted experimental verification. For example, Sarocladium strictum (syn. Acremonium strictum), a widespread soil-inhabiting and rootendophytic fungus, is sometimes isolated from ericoid roots and may form "atypical [ericoid] mycorrhizae," i.e., loose intracellular hyphal complexes, in the rhizodermis of ericoid plants (Xiao and Berch 1996). However, Grunewaldt-Stöcker and von Alten (2016) found S. strictum hyphae only in cells "that were dead or in the process of dying" and concluded that this mycobiont "does not behave like a common ErMFif it is one at all." Some claims are not substantiated at all and therefore must be rejected-for example, Zhang et al. (2009) "confirmed one basidiomycete strain as a putative ErMF", because it "formed coil-like mycorrhizal structures in the roots of Rhododendron fortunei in vitro and showed positive effects on the seedlings of $R$. fortune $i$ ", but provided no data to support these statements (in fact, a description of these "effects" and how the authors evaluated them is missing in that paper). In contrast, the authors noted that "the mycorrhizal infection rate of the strain was quite low" in their in vitro resynthesis. In addition, the recovery of the basidiomycetous strain from the Rhododendron roots was very low (only one isolate out of the 220 obtained) and BLAST searches in GenBank at NCBI (see below, accessed 7 January 2020) showed that its ITS nuc-rDNA sequence (EU888636) displays 100/100\% coverage/ similarity to several sequences of Trametes hirsuta, a known plant pathogen/wood decaying saprobe. Despite that the presence of Trametes in Rhododendron roots is interesting (and that basidiomycetous soil saprobes may actually improve growth and fruiting of ericoid plants, see Vohník et al. 2012b), such claims do not help to understand the diversity of true ErMF and are therefore discouraged.

10 Besides ErMF, ericoid plants associate with a wide range of root fungal endophytes, the most prominent (at least in the temperate and boreal regions of the Northern Hemisphere) being the dark septate endophytes (DSE) from the Phialocephala fortinii s. 1.-Acephala applanata species complex (PAC, Helotiales: Mollisiaceae, see Grünig et al. 2008) that often dominate cultivable spectra of ericoid root mycobionts. PAC currently contains 21 characterized, morphologically indistinguishable but genetically isolated Phialocephala s. 1. cryptic species and seven of them have scientific names (Stroheker et al. 2016). However, their molecular distinguishing is a complicated issue (see Grünig et al. 2007) that cannot be based on ITS nuc-rDNA sequences (Grünig 2004). Despite that some PAC/DSE isolates can form intracellular hyphal coils/loops in the rhizodermis of ericoid plants (Vohník et al. 2003; Usuki and Narisawa 2005 ) and that DSE commonly form "partial mantles" on the surface of ericoid roots (e.g., Rains et al. 2003, also see Peterson et al. 2008), there are no solid proofs available so far that these mycobionts are beneficial associates of ericoid plants. In contrast, they often have neutral to negative effects on performance of ericoid plants in vitro (see Lukešová et al. 2015) and genomes 
of the so far sequenced DSE fungi combine saprobic and pathogenic rather than mutualistic traits (Schlegel et al. 2016; Knapp et al. 2018). However, since naturally DSE-colonized ericoid plants typically appear healthy, research on DSE/PAC functioning in ericoid roots under conditions closer to nature, including their interactions with ErMF (cf. Vohník et al. 2005), is encouraged.

11 Hyaloscypha variabilis and $O$. maius frequently inhabit non-ericoid EcM roots as endophytes, i.e., they do not form the respective ectomycorrhizae (e.g., Schild et al. 1988; Summerbell 2005; Vohník et al. 2013). Hyaloscypha hepaticicola also forms a characteristic mutualistic symbiosis (mycothallus) with certain liverworts (Duckett and Read 1995; Kowal et al. 2018).

\section{Methodological guide}

This simplified guide focuses on the traditional methodology used in the ErM research and includes basic advices on root sample collection and handling, microscopic observations and photo-documentation, root mycobiont isolation and maintenance of the obtained isolates, isolate identification, and resynthesis experiments. For a seminal account of various experimental approaches to the ErM symbiosis, see "Experiments with ericoid mycorrhiza" by Leake and Read (1991). Many methods used in the ErM research have been adopted from the $\mathrm{AM} / \mathrm{EcM}$ research, and interested readers are referred to the excellent handbook "Working with mycorrhizas in forestry and agriculture" by Brundrett et al. (1996) that, however, lacks a text specifically focusing on the ErM symbiosis.

\section{Root sample collection and handling}

\section{Things to consider}

1 Over 2700 ericoid species, ranging from arctic/alpine mini-shrubs to Rhododendron trees reaching up to $30 \mathrm{~m}$, inhabiting various ecosystems from waterlogged swamps to dry sclerophyllous forests, comprising terrestrial, hemi-epiphytic, and epiphytic growth forms, potentially form ericoid mycorrhizae (Luteyn 2002; Stevens et al. 2004; Kron and Luteyn 2005; Freudenstein et al. 2016). This vast variety should be taken into account when selecting an appropriate sampling protocol and choosing suitable equipment. For example, while developed heathlands typically comprise a thick layer of organic matter with ericoid roots confined to first ca. $15-20 \mathrm{~cm}$ (Fig. 1a), ericoid plants also thrive in soils with low organic content and their roots may penetrate deep into the mineral horizon (Fig. 1b), making their unearthing a (very) strenuous activity.

2 Seasonal effects on ErM colonization and ErMF diversity and distribution are poorly understood (cf. Kemp et al. 2003). Samples are typically taken at the end of the growing season when suitable soil humidity (in terms of both hair root and ErMF community development) can be expected.

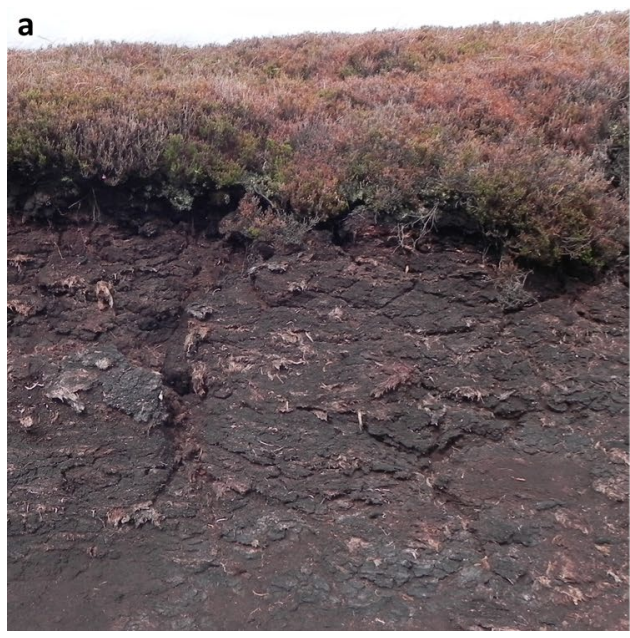

Fig. 1 Soil profiles from two contrasting sites inhabited by ericoid plants. While developed heathlands typically comprise a thick layer of organic matter with ericoid roots confined to first ca. $15-20 \mathrm{~cm}$ (as illustrated on the example of heather (Calluna vulgaris) from Langsett Moors, UK (a)), ericoid plants also thrive in soils with low

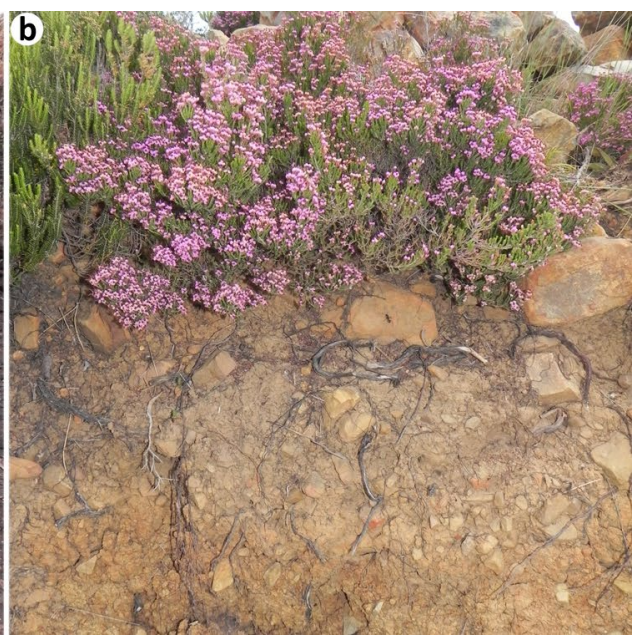

organic content and their roots may penetrate deep into the mineral horizon (as illustrated on the example of Erica sp. from a village close to Mellousa, Morocco (b)). The organic layer in $\mathbf{a}$ is $>1 \mathrm{~m}$ thick, the mineral layer in $\mathbf{b}$ is ca. $50 \mathrm{~cm}$ thick 
Under favorable conditions, ericoid plants produce abundance of delicate roots that are often difficult to separate from soil organic matter (small pieces of peat and wood, needles, etc., Fig. 2). Additionally, minuscule alpine and (sub-)arctic ericoid species often grow intermingled with AM/EcM vegetation (Fig. 3) and selection of their fine roots may turn into a very difficult task requiring a lot of time, experience, and a reasonable stereomicroscope. At the same time, proper separation of ericoid roots from those of the surrounding vegetation is absolutely crucial to the success of all subsequent activities and, as such, should be approached with maximal caution and patience (cf. the Cenococcum, Rhizopogon, and Thelephora EcM morphotypes observed in various ericoid plants by Largent et al. (1980), Dighton and Coleman (1992), and Smith et al. (1995) and especially the AM colonization observed by Dighton and Coleman
Fig. 2 Vigorous root system of highbush blueberry (Vaccinium corymbosum) cv. Misty. Under favorable conditions, ericoid plants produce abundance of delicate roots that are often difficult to separate from soil organic particles (small pieces of peat and wood, needles, etc.)

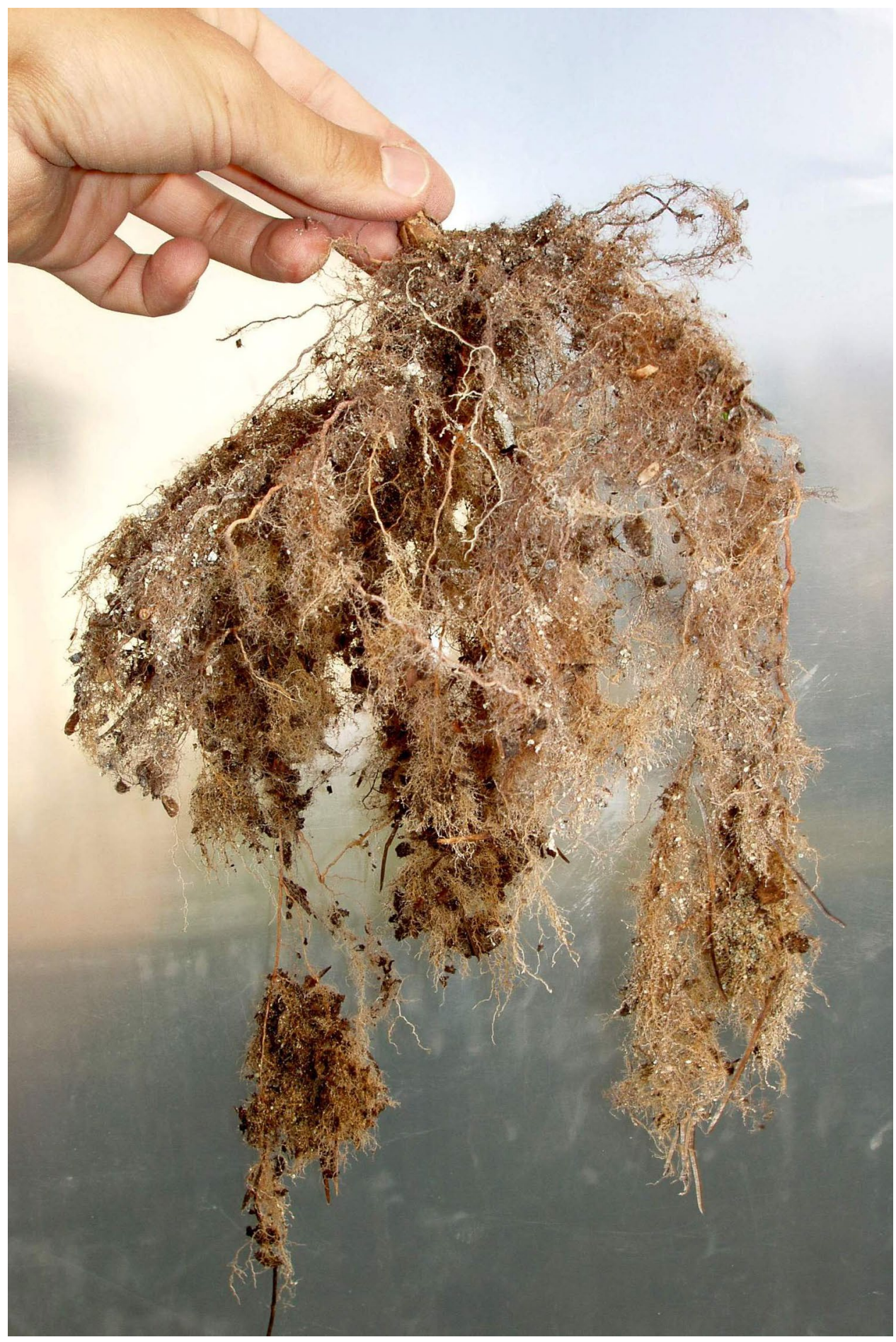



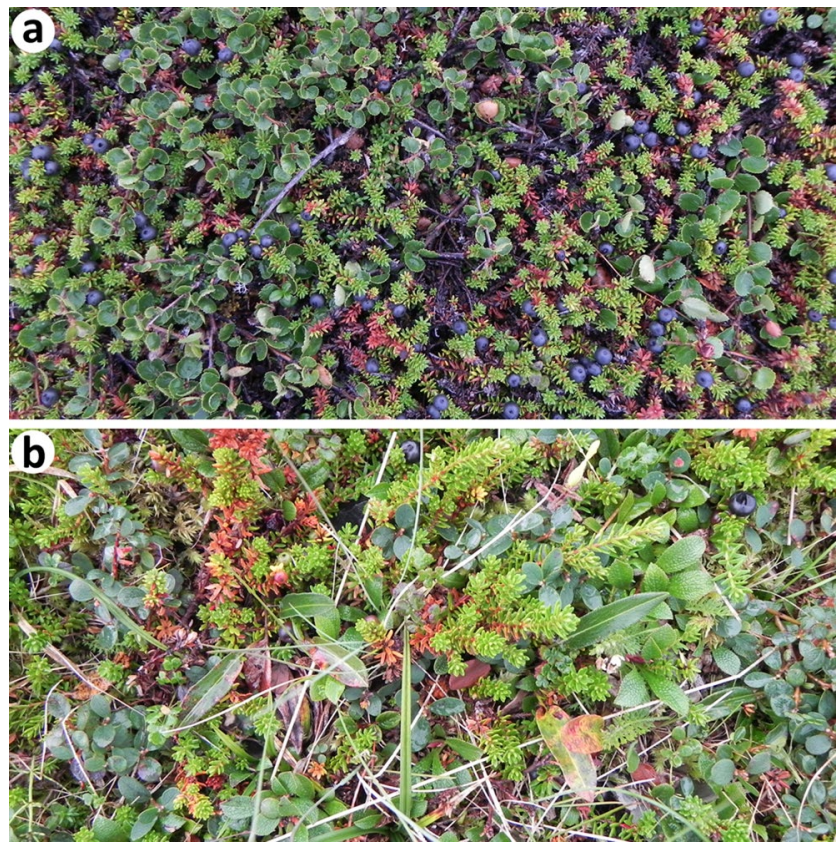

Fig. 3 Subarctic ericoid shrubs growing intermingled with AM and EcM vegetation. Minuscule alpine and (sub-)arctic ericoid species often grow intermingled with $\mathrm{AM}$ and/or EcM vegetation and distinguishing of their delicate hair roots may turn into a very difficult task requiring a lot of time, experience, and a reasonable stereomicroscope. a Empetrum nigrum growing intermingled with Betula nana (Betulaceae), which forms ectomycorrhizae. b E. nigrum and Vaccinium uliginosum growing intermingled, among others, with some AM grasses and EcM Salix sp. Both photos taken at Gamvík, northern Norway

(1992) in Rhododendron maximum "beaded roots" (see Fig. 1 in that paper); the fact that these contained "between 5-10 layers of cortical cells and produced abundant root hairs from the epidermis" casts doubts as to whether they actually belonged to the targeted $R$. maximum individuals).

Ericoid plants are best sampled intact with the mycorrhizosphere soil attached to the root system. Immediate transport to the laboratory and sample processing (ideally within $24 \mathrm{~h}$ from sampling) is necessary to prevent preferential development of fast growing endophytes, saprobes, and pathogens. The mycorrhizosphere soil is best removed with aid of a suitable sieve and tap water; even maximal tap flow is typically not enough and an adapter with a flexible rubber hose facilitating flow control always comes in handy (Fig. 4), saving hours of inefficient labor (e.g., cleaning hair roots from soil particles using a small brush or tweezers). High-order lateral roots with attached hair roots are separated from the washed root system using scissors or a scalpel and placed in a large Petri dish with tap water. Healthy-looking hair roots are the very thinnest turgescent whitish/yellowish roots with characteristic anatomy (i.e., inflated rhizodermal cells, reduced cortex) and morphology (i.e., lacking root hairs, an important criterion distinguishing them from the majority of non-ericoid roots). Individual healthy-looking undamaged hair roots are separated with a scalpel under a stereomicroscope and processed as detailed below.

The storage conditions depend on the intended use of the root samples-those for microscopy and especially for mycobiont isolation should be processed immediately while those for direct DNA isolation can be, after surface sterilization (alternatively followed by drying), stored in a freezer.

In mycology, it is mandatory to deposit vouchers for name-bearing types in a publicly accessible reference collection, but vouchers are necessary "not only when new fungi are described, but also in connection with any scientific study, whether by taxonomists, systematists, physiologists, chemists, molecular biologists, pathologists, ecologists, clinicians, etc., dealing with organisms" (Agerer et al. 2000). This applies "not only to fruit-bodies, but indeed to any other form of fungal structure, such as sclerotia or ectomycorrhizas" (Agerer et al. 2000), hence also to ericoid mycorrhizae. Therefore, deposition of ericoid root samples in a way that they are accessible for other scientists and suitable, e.g., for microscopy and DNA isolation, is encouraged (e.g., deposition in a public herbarium of washed ericoid roots in $30-50 \%$ ethanol for microscopy and surfacesterilized + dried hair roots for DNA isolation), despite that it is not customary to do so.

\section{Microscopic observations and photo-documentation}

For technical terminology regarding stereomicroscopes (=dissecting microscopes) and compound microscopes, see Fig. 1.13 in Brundrett et al. (1996); for a brief introduction to working with microscopes, see Chap. 1.7 in the same handbook.

\section{Things to consider}

1 ErM colonization occurs in the thinnest parts of the ericoid root system and while AM and EcM root colonization can be observed, counted and documented using a good stereomicroscope, such an approach is of little use when working with ericoid hair roots. The characteristic ErM hyphal coils are tiny structures and "detailed study of intracellular hyphal development [in ericoid mycorrhizae] is almost beyond the power of resolution of the light microscope" (Read 1983). On the other hand, such details as hyphal clamps on basidiomycetous hyphae forming loose intracellular loops in the rhizodermis of ericoid hair roots can be observed using a well-prepared material and a reasonably equipped compound microscope (see Fig. 1 
Fig. 4 Removing rhizosphere soil from fine ericoid roots.

The rhizosphere soil is best removed with aid of a suitable sieve and tap water; even maximal tap flow is typically not enough and an adapter with a flexible rubber hose facilitating flow control always comes in handy, saving hours of inefficient labor (e.g., cleaning hair roots from soil particles using a small brush or tweezers)

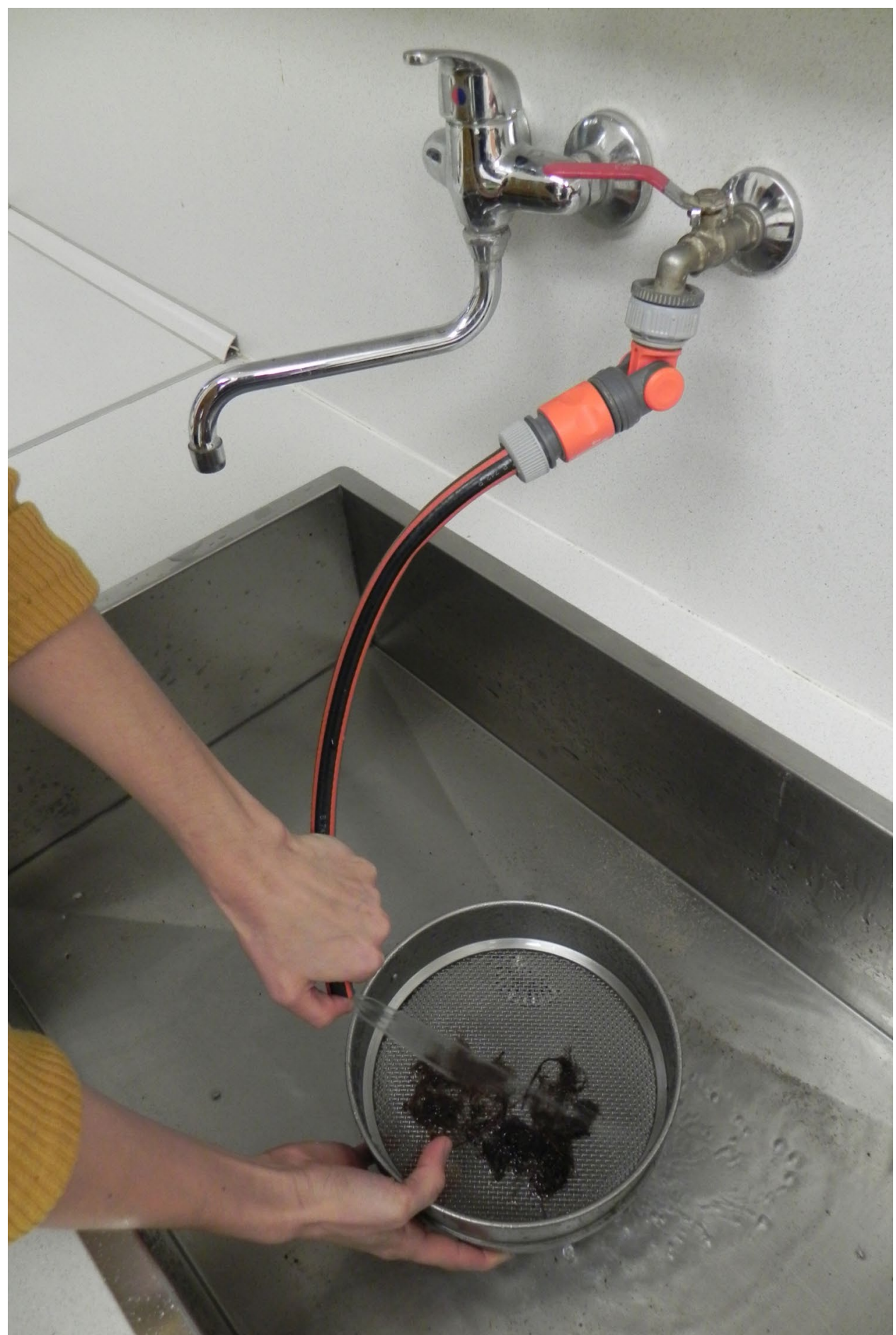

in Vohník and Albrechtová 2011 and Fig. 3d in Vohník et al. 2012a).

2 Compared to the AM arbuscules and the EcM Hartig net, the ErM intracellular hyphal coils are morphologically very simple structures that may be confused with intracellular haustoria of certain fungal/ oomycetal parasites (cf. Fraymouth 1956; Rajendren 1972) and, generally speaking, intracellular hyphal coils/loops formed by fungi not regarded as true ErMF (cf. Vohník et al. 2007; Lukešová et al. 2015; Grunewaldt-Stöcker and von Alten 2016). Indeed, the true ErMF phylogenetically overlap with plant parasites and endophytes as well as free-living saprobes and Tedersoo et al. (2009) suggested that "Ericales evolved capacities to host these endophytes in individual root cells and stimulated the formation of coils for improved 
nutrient exchange, thus giving rise to the ericoid mycorrhiza." Hence, when observing and describing naturally colonized ericoid hair roots, one has to bear in mind that these often represent variegated mosaics of different kinds of fungal colonization (ErM + non-ErM, see Fig. 1 in Bruzone et al. 2015) at different stages of development and that not every intracellular hyphal coil/loop in the rhizodermis of an ericoid hair root necessarily represents ericoid mycorrhiza (e.g., Fig. 3F in Villarreal-Ruiz et al. 2004).

3 Other parts of ericoid root systems than the hair roots may possess different colonization patterns (and different mycobionts). For example, the four Hawaiian ericoid species investigated by Koske et al. (1990) exhibited a dense AM colonization in coarse roots ( $>1.5 \mathrm{~mm}$ in diameter) while the hair roots were colonized in the manner typical for ericoid mycorrhiza. Congruently, Gemma and Koske (1990) noted that in the two Hawaiian ericoid species investigated, the AM colonization occurred "in the cortex of their older roots in addition to the ericoid mycorrhizae present in their fine hair roots".

4 Even in twenty-first century, careful screening of root systems using a stereomicroscope/compound microscope may lead to interesting discoveries (e.g., Setaro et al. 2006; Okuda et al. 2011; Vohník et al. 2012a, 2015).

Washed pre-selected ericoid hair roots have to be cleared and their fungal colonization visualized by suitable staining. An easy protocol modified from Phillips and Hayman (1970) that works well for both field collected and in vitro grown ericoid plants is as follows: roots are autoclaved in $10 \%$ potassium hydroxide $(\mathrm{KOH})$ at $121^{\circ} \mathrm{C}$ for ca. $20 \mathrm{~min}$ (depending on their origin and age), then washed with tap water, acidified by brief washing in 3\% hydrochloric acid $(\mathrm{HCl})$, washed with tap water, autoclaved in a $0.05 \%$ solution of trypan blue in lactoglycerol (glycerol/lactic acid/ water 2:1:2) at $121{ }^{\circ} \mathrm{C}$ for ca. $10 \mathrm{~min}$ and washed with tap water. Excess trypan blue can be removed by leaving the stained roots in lactoglycerol overnight at room temperature/ for several days in a fridge. Trypan blue is a possible carcinogen and its excess solution should be collected and disposed of in accordance with corresponding regulations. Alternatively, trypan blue solution can be substituted by a nontoxic ink-vinegar solution (Vierheilig et al. 1998). A cooker or a water bath can be used in the absence of an autoclave; alternatively, roots can be left in $10 \% \mathrm{KOH}$ at room temperature for 1-2 days and then in the trypan blue-lactoglycerol or ink-vinegar solution overnight. When processing larger amounts of root samples, a suitable bottle top dispenser compatible with the chemicals used always comes in handy. For alternative methods of root clearing and staining, see Chap. 4.2 in Brundrett et al. (1996) and Vierheilig et al. (2005); for vital staining of ericoid hair roots, see Grunewaldt-Stöcker et al. (2013) and GrunewaldtStöcker and von Alten (2016).

Individual hair roots are mounted into a glass slide with a small drop of lactoglycerol that has much lower desiccation rate than water (such slides can be stored without any special treatment for many days in a fridge). For an illustrative photo-documentation, it is suggested to provide (1) a general view of the colonized roots at lower magnifications $(\times 200-400)$ and (2) a detailed view of individual colonized rhizodermal cells at a high magnification $(\times 1000)$ (see Figs 6 and 7 in Fehrer et al. 2019). The latter is best obtained using an oil immersion objective combined with differential interference contrast ( $=$ Nomarski interference contrast) (see Fig. 5 in Bruzone et al. 2017). High magnification photos of longitudinal and transversal sections warrant the best illustration of the root colonization pattern. However, since the ericoid hair roots are too tiny for hand sectioning, paraffin thin sections (or an alternative) have to be obtained (Fig. 5; also see Figs. 1a-c in Vohník et al. 2012a). The 3D arrangements of intracellular hyphae can be explored using laser scanning confocal microscopy (see Figs. 14-20 in Massicotte et al. 2005), the ultrastructural details by transmission electron microscopy (see Plates 2 and 3 in Bonfante-Fasolo and Gianinazzi-Pearson 1979), and the hyphal mantle morphology by scanning electron microscopy (SEM, see Fig. 1d in Vohník et al. 2012a), while attempts of imaging the intracellular ErM colonization by SEM are usually of little use (see Figs. 2-5 in McLean and Lawrie 1996). However, these advanced methods are outside the scope of this guide.

The extent of fungal colonization is an important variable that should be assessed in field-collected as well as in vitro grown host roots and that is typically omitted in recent ErM studies. Prior to any assessment, a representative root sample must be obtained (see Giovannetti and Mosse 1980); this may be, however, complicated in the case of especially vigorous ericoid root systems. While the gridline intersection method in combination with a stereomicroscope (Giovannetti and Mosse 1980, also see Fig. 4.3 in Brundrett et al. 1996) works well with AM and EcM roots, it is of no use for estimating the ErM colonization. The magnified intersections method employing a compound microscope (McGonigle et al. 1990, see Fig. 4.4 in Brundrett et al. 1996) is commonly used in the AM research and sometimes also in the ErM research, but its suitability for the tiny ErM hair roots has not been thoroughly tested. Some authors calculated total \% colonization based on screening of adjacent rhizodermal cells in random hair root segments (e.g., Dalpé 1986; McLean et al. 1998; Vohník and Albrechtová 2011) that works well especially for in vitro grown plants with small root systems. On the other hand, this method is suitable neither for very heavy (e.g., when the intracellular 


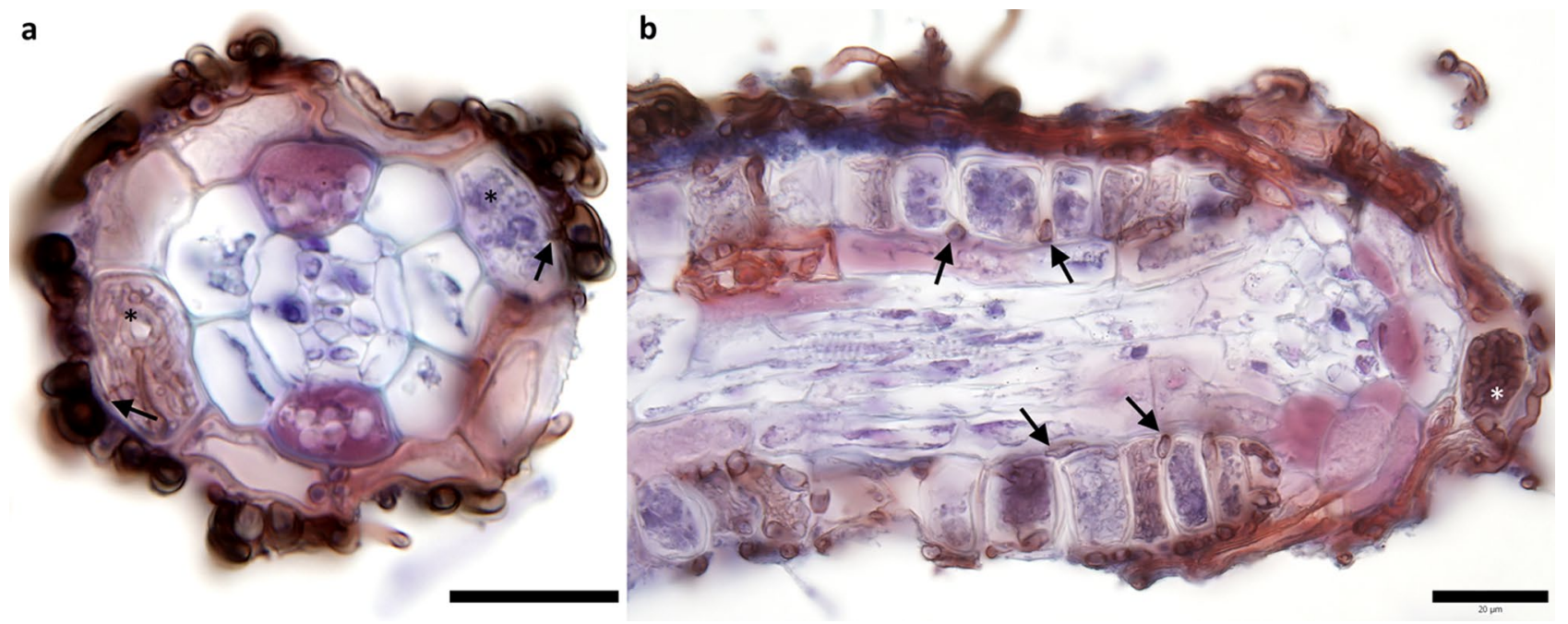

Fig. 5 Transversal and longitudinal sections through hair roots of European blueberry. High magnification photos of longitudinal and transversal sections warrant the best illustration of the root colonization pattern. However, since the ericoid hair roots are too tiny for hand sectioning, paraffin thin sections (or an alternative) have to be obtained. a Thick dark brown surface hyphae that, upon entering the rhizodermis, dramatically change their diameter and give rise to intracellular hyphal coils morphologically corresponding

hyphal coils are masked by thick melanized superficial hyphae or mantles) nor very low (a few cells per root system) colonization and in such cases a semi-quantitative estimation based on abundance classes may be a more appropriate option (e.g., very rare $=$ few isolated colonized cells in the whole root system, rare $=$ few groups of adjacent colonized cells, common $=$ tens to hundreds of colonized cells dispersed throughout the whole root system, dominating $=$ most of the root system colonized, etc.). Especially in the field-collected roots, it is very important to define (and document!) individual colonization patterns, including the surface hyphae/hyphal mantles, and to measure their extent separately. On the other hand, this can be a very complex task as, e.g., thick melanized superficial hyphae may change their diameter and color when colonizing intracellular spaces of the rhizodermal cells (cf. Fig. 5a), the same mycelium may form intracellular structures typical for DSE and at the same time intracellular hyphal coils typical for ErMF in adjacent cells, etc. (see Fig. 6, cf. Vohník and Albrechtová 2011; Sadowsky et al. 2012). This is, however, the reality of the naturally colonized ErM hair roots and we have to cope with it.

\section{Root mycobiont isolation and maintenance of the obtained isolates}

For general introduction to various procedures used for isolation of microorganisms from plant tissues, see Sieber (2002) and Hallmann et al. (2006). Most if not all methods to ericoid mycorrhiza (asterisks). Note hyphal connections between the surface hyphae and the intracellular hyphal coils (arrows). b Note the thick brownish intercellular hyphae (arrows) and an intracellular microsclerotium developed at the very tip of the hair root (asterisk). Both photos naturally colonized Vaccinium myrtillus hair roots collected in Northern Bohemia (Czechia), the sections were stained with acid fuchsin and trypan blue. Bars $=20 \mu \mathrm{m}$

for isolate maintenance were adopted from the EcM research and interested readers are referred to, e.g., Molina and Palmer (1982), Heinonen-Tanski and Holopainen (1991) and Chap. 5.3. in Brundrett et al. (1996). The described techniques are aseptic and this can be facilitated by the use of a (laminar) flow hood and a gas burner in a clean environment. On the other hand, when controlled laboratory conditions are not available (longer field trips, unpopulated areas, etc.), root mycobionts can be effectively isolated with a help of a portable flow hood and an alcohol burner/lighter, provided that basic hygiene rules are maintained.

\section{Things to consider}

1 Ericoid mycorrhiza in an endomycorrhizal type characterized by fine compact intracellular hyphal coils formed in the rhizodermis of healthy ericoid hair roots; hence, all isolation techniques must target healthy ericoid hair roots. Using damaged or moribund hair roots, thicker suberized roots that typically lack rhizodermis (see Fig. 1 in Hamim et al. 2017) as well as hair root clumps or "fine root threads" (see Lorberau et al. 2017) favors growth of non-ErM fungi and is therefore discouraged. That said, the distribution of different mycobionts within the ericoid root system as affected by root age/diameter/order is poorly understood (cf. Fig. 1 in Allen et al. 2003 and Fig. 1 in Midgley et al. 2004). 


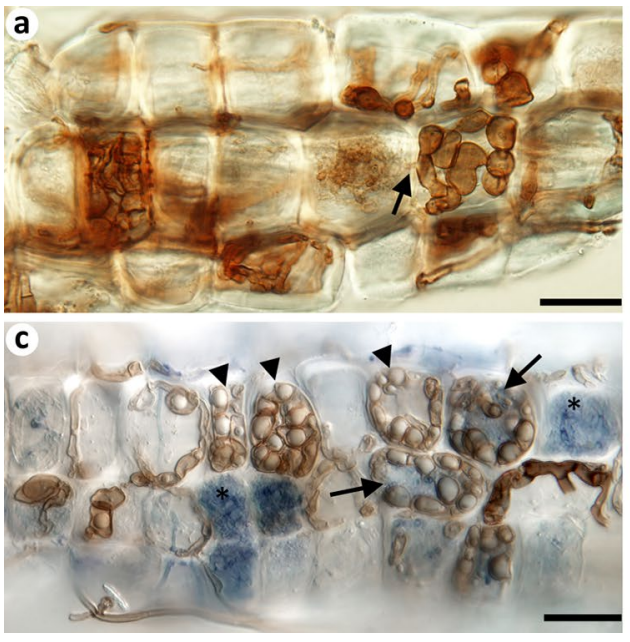

Fig. 6 Miscellaneous natural colonization of ericoid hair roots. a Note the hyphal connection (arrow) between the intracellular hyphal coil (left) and the dark brown hyphal structure (right) morphologically resembling a developing intracellular microsclerotium, i.e., a structure typical for DSE mycobionts. b Rhizodermal cells filled with compact hyphal coils morphologically corresponding to ericoid mycorrhiza (asterisks), accompanied by cells containing loose coils formed by dark brown septate hyphae that morphologically correspond to the DSE-association. Both colonization patterns may be formed by the same mycobiont (cf. Vohník and Albrechtová 2011). Note the hyphal connections between some neighboring cells (arrows). c A very common combination of

2 There may be as many as 250-2000 fungal entry points per $1 \mathrm{~cm}$ of the root length in Calluna vulgaris seedlings (Goulart et al. 1993), and in principle, every single rhizodermal cell may be colonized by a different fungus (a different species or a genetically different individual of the same species). Despite that this is probably rarely happening under natural conditions where individual ericoid root systems may be colonized by a single or just a few dominating mycobionts (cf. Midgley et al. 2002, 2004), this chance has to be kept in mind when preparing root segments for mycobiont isolation. The basic rule is the shorter the better-while the minimal root segment length suitable for handling with fine forceps/tweezers is $\sim 2 \mathrm{~mm}$, using segments longer than $3 \mathrm{~mm}$ significantly increases the chance of obtaining fast growing endophytes (e.g., those belonging to PAC) or casual saprobes at the expense of the relatively slow growing ErMF.

3 Ericoid hair roots are delicate and ephemeral structures with high turnover rates, thus some parts of the ericoid root system are always in the process of degeneration/ decomposition (see Fig. 5 in Grunewaldt-Stöcker et al. 2013). Indeed, the active lifespan of the colonized rhizodermal cells is "not more than five or six weeks" (Smith and Read 2008a), and eventually, both the phytobiont and the mycobiont lose their integrity,

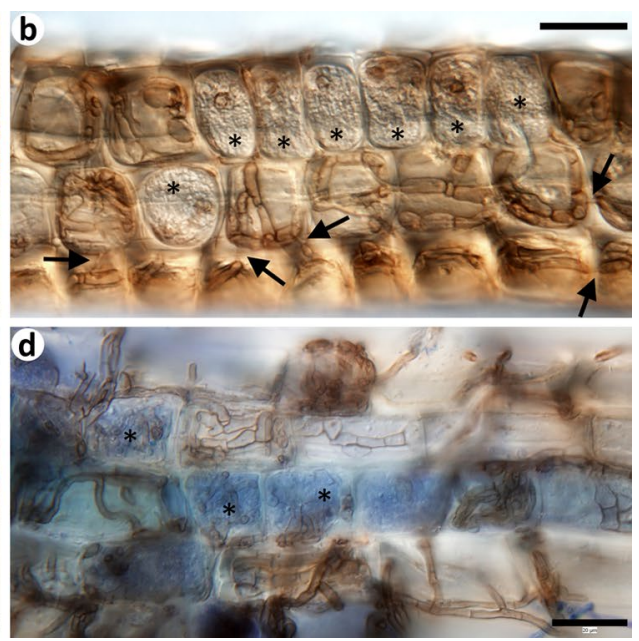

the ErM colonization pattern (compact fine hyphal coils, asterisks) and the DSE microsclerotia in various stages of development (arrowheads). Note that in some cells, both patterns are combined (arrows), meaning either they are formed by the same mycobiont or the cells are colonized by at least two different mycobionts. $\mathbf{d}$ Another example of a combination of ErM + DSE colonization patterns. Note cells filled with hyphae changing their color (asterisks). All roots (a Erica sp., Tunisia, brightfield microscopy); b-d Vaccinium myrtillus, Czechia, brightfield microscopy with Nomarski interference contrast) cleared with $\mathrm{KOH}$, in $\mathbf{c}$ and $\mathbf{d}$ additionally stained with trypan blue (see the section "Microscopic observations and photodocumentation"). Bars $=20 \mu \mathrm{m}$

resulting in a dead cell containing residues of earlier fungal colonization (Duddridge and Read 1982, also see Fig. 2d in Vohník et al. 2016a). Since it is not entirely possible to distinguish single deteriorated/moribund cells (that may be already taken over by parasites or saprobes) even with a good compound microscope (cf. Figs 7 and 8 in Grunewaldt-Stöcker and von Alten 2016), not every isolate obtained from a surfacesterilized hair root segment necessarily represents an ErMF- "the occurrence of a given fungus is clearly not synonymous with its being mycorrhizal, although it is widely interpreted as being so" (Leake and Read 1991).

4 ErMF show no host specificity, i.e., roots of coexisting genetically different ericoid plants (different cultivars/ species) usually harbor comparable ErMF communities (Walker et al. 2011; Foster et al. 2020; also see Straker 1996).

5 The isolation procedure "should be sensitive enough to recover endophytic [i.e., living inside the investigated root] microorganisms, but at the same time be strong enough to eliminate epiphytes from the root surface" (Hallmann et al. 2006; also see Fig. 1 in Sieber 2002).

6 Since "it is a fundamental principle of science that research work must be reproducible" and that "reproducibility requires that studies can be made using the same material or cultures as the original study 
used" (Agerer et al. 2000), a deposition of representative isolates of ericoid root mycobionts in established public collections/herbaria is strongly encouraged.

While the first isolates of $H$. hepaticicola had been obtained from ericoid hair roots using the maceration method (i.e., incubation of a suspension of detached hair root cells), practically all following studies employed some modifications of the direct plating method (i.e., incubation of hair root segments; for details see Pearson and Read 1973b). Smith and Read (2008a) argued that the latter approach "will yield a mixture of ErM and non-mycorrhizal fungi, but the origin of any one of them in the root piece remains in doubt". However, also the maceration method cannot discriminate between ErMF and intracellular endophytes/parasites, the detached rhizodermal cells may be already dead or in the process of dying (possibly being already colonized by saprobes), they may be mixed with detached cortical cells typically free of ErMF but containing endophytes, etc. On the other hand, in contrast to the (direct) plating method, the maceration method does not select for fast growing fungi, provided that the individual detached rhizodermal cells are incubated separately and each cell is being colonized by a single mycobiont (which is not necessarily true for all ErM rhizodermal cells, see Selosse et al. 2007). Hence, the maceration method could be especially efficient for recovery of slow-growing ericoid root mycobionts (see below).

The maceration method requires a good (preferably inverted) compound microscope for localization of the detached cells and screening of the development of the emerging fungal hyphae that is crucial for distinguishing intracellular mycobionts from casual surface-dwelling contaminants (given their tiny and translucent nature, the same can actually be done with hair root segments). While the first critical step is the maceration itself (according to Pearson and Read (1973b), hair roots segments have to be macerated "for a period sufficient to detach most of the cortical cells from the central stele" and this, according to my experience, may take 1-3 days, thus inevitably biasing the resulting mycobiont spectrum), also the next steps require a higher level of experience with basic microbiological techniques. Pearson and Read (1973b) preferred the maceration method to the direct plating method, arguing that the latter "yielded most of the fast growing organisms of the rhizosphere whereas the maceration technique selected only those organisms most intimately associated with the root". However, the hair root segments used for the maceration were first washed for $2 \mathrm{~h}$ under running tap water and subsequently transferred through 20 to 25 washes in sterile water (each lasting $5 \mathrm{~min}$ ) whereas the segments used for the direct plating remained without any such treatment (Pearson and Read 1973b). Apparently, some means of surface treatment effective in avoiding contamination by casual surface dwelling mycobionts is necessary (cf. Newell and Fell 1982 and Vohník et al. 2016b). For example, Lorberau et al. (2017) investigated Cassiope tetragona root samples that were not serially washed or surface-sterilized and reported that the detected mycobiont communities were "dominated by fungal groups in the Basidiomycota traditionally classified as either saprotrophic or EcM symbionts," while only a minor part "could be annotated as ErM-forming fungi". The lack of appropriate root selection and surface treatment casts doubts as to whether $C$. tetragona might really be "forming mycorrhizal symbioses with typically EcM-forming fungi," as hypothesized by Lorberau et al. (2017).

The first isolates of $H$. hepaticicola had been obtained from serially washed (i.e., not surface-sterilized) hair roots but the majority of subsequent studies employed some kind of root surface sterilization. Smith and Read (2008a) argued that "exposure of delicate hair root segments to sterilants, most commonly solutions of hypochlorite or hydrogen peroxide, will lead to a selective reduction [in the number of obtained ErMF isolates]" as "it has long been known that chemical sterilants, even when applied at low concentrations and for short durations, can kill internal as well as external fungal occupants of hair roots". Serial washing requires tap water running for several hours and considerable amounts of sterile water and laboratory equipment. Since it cannot completely eliminate, e.g., living extraradical hyphae/ fungal spores firmly attached to the root surface (but without penetration inside the root), the combination of serial washing and isolation of mycobionts from hair root segments may lead to a selective increase in the number of obtained isolates, hence to an overestimation of the diversity of true ericoid root mycobionts.

To conclude, (1) the more equipment-, time-, and waterdemanding nature of serial washing of the hair roots followed by their maceration is not necessarily counterbalanced by better results and (2) plating of short ( $2 \mathrm{~mm}$ in length) surface-sterilized segments of healthy hair roots is suggested as a reasonable procedure for characterization of the cultivable mycobiota of the ericoid hair roots. That said, it would be interesting to directly compare these two methods in terms of their efficacy in recovering ericoid root mycobionts/true ErMF.

\section{Plating of surface-sterilized hair root segments}

Pre-selected (preferably using a stereomicroscope) washed healthy-looking hair roots have to be surface-sterilized to avoid contamination by surface dwelling organisms and their propagules. This is commonly done by ethanol (>95\%), solutions containing active chlorine like sodium hypochlorite $(\mathrm{NaClO})$ or calcium hypochlorite $\left[\mathrm{Ca}(\mathrm{ClO})_{2}\right]$, solutions containing hydrogen peroxide $\left(\mathrm{H}_{2} \mathrm{O}_{2}\right.$, usually 
$>30 \%$ ) and consecutive combinations of these (cf. Table 1 in Sieber 2002 and Table 17.1 in Hallmann et al. 2006). Two important variables are the treatment time and the sterilant concentration and, not surprisingly, their different combinations will have a significant effect on the detected cultivable mycobiota (see Newell and Fell 1982 and Fig. 1 in Sieber 2002). After surface sterilization, the applied sterilant(s) must be removed from the roots by consecutive washes in sterile water. Hair root pre-treatment with surfactants is not necessary. A diluted household bleach can be used instead of reagent grade chemicals. Hydrogen peroxide and chlorine are caustic substances that should be treated as such, i.e., with high caution.

Washed surface-sterilized hair roots are aseptically cut into $\sim 2$-mm-long segments, and these are plated on the surface of a chosen solid medium amended with antibiotics to prevent the growth of bacteria (Brown (1924a) describes simple procedures for rescuing bacteria-contaminated mycelial cultures that may come in handy should antibiotics fail). A sterility check can be performed before plating by imprinting the root segments onto the same medium in separate dishes. Readily available media include $2 \%$ malt agar (Pearson and Read 1973b) and potato dextrose agar (PDA) that are easy to prepare but unsuitable for longterm storage and subculturing of the obtained isolates as they obtain too high levels of sugars; the synthetic modified Melin-Norkrans medium (MMN, Marx 1969) that is, after reducing the amount of glucose (e.g., to 1/10) and omitting maltose, also suitable for in vitro resynthesis experiments with ericoid plants; the inexpensive and easy-to-prepare potato carrot agar (PCA) suitable for long term storage and subculturing of the obtained isolates (various modifications of the original recipe, see Gams et al. 1998); malt-yeastpeptone medium (MYP) also suitable for cultivation of the serendipitoid fungi (see Vohník et al. 2016a); and modified Leonian's agar (MLA, Malloch 1981) that seems to be the best medium for long term storage and subculturing of all fungal isolates I have so far tested, including the serendipitoid fungi. If time and space permits, it is advisable to use more than one isolation medium, including selective media favoring growth of certain fungal guilds (e.g., addition of benomyl suppresses the growth of many ascomycetes that results in an increased recovery of basidiomycetes (e.g., Schild et al. 1988, but see Bruzone et al. 2015)). Dishes with plated segments are sealed by an air permeable foil/tape and incubated in the dark at room temperature.

First fungal hyphae may emerge from the hair root segments within 2 days so it is advisable to check the dishes daily, at least during the first 2-3 weeks after plating. Fastgrowing and sporulating mycelia are typically discarded as contaminants; they may produce submerged hyaline hyphae and grow unnoticed until contaminating most of the dish while others may immediately sporulate that typically leads to a loss of the whole dish. An effective solution is to use multi-compartment plastic square dishes (Fig. 7), which are also more convenient for long-term storage. When contaminated, individual compartments can be covered with 3-mm layer of table salt carefully dispersed over the surface of the medium, a procedure much more effective in stopping the spread of the contamination than any attempts to "clean" them, e.g., by removing the contaminated medium (personal observation). However, although relatively mild, table salt is a desiccant so in the long term, such a treatment may dehydrate the medium also in the remaining noncontaminated compartments.

Typical ErMF like H. hepaticicola emerge during the first month of cultivation and are considered slowgrowing, despite that the recovery of real slow-growing root mycobionts may take many months-a likely record holder is the seagrass symbiotic ascomycete Posidoniomyces atricolor (Vohník et al. 2019) with new colonies still emerging from surface-sterilized root segments after a 1.5-year-long incubation (personal observation). However, since many ericoid mycobionts actually grow relatively fast, practically all isolation attempts terminate after several weeks (typically no more than 2-3 months) and it is therefore unknown whether similarly slow-growing mycobionts occur

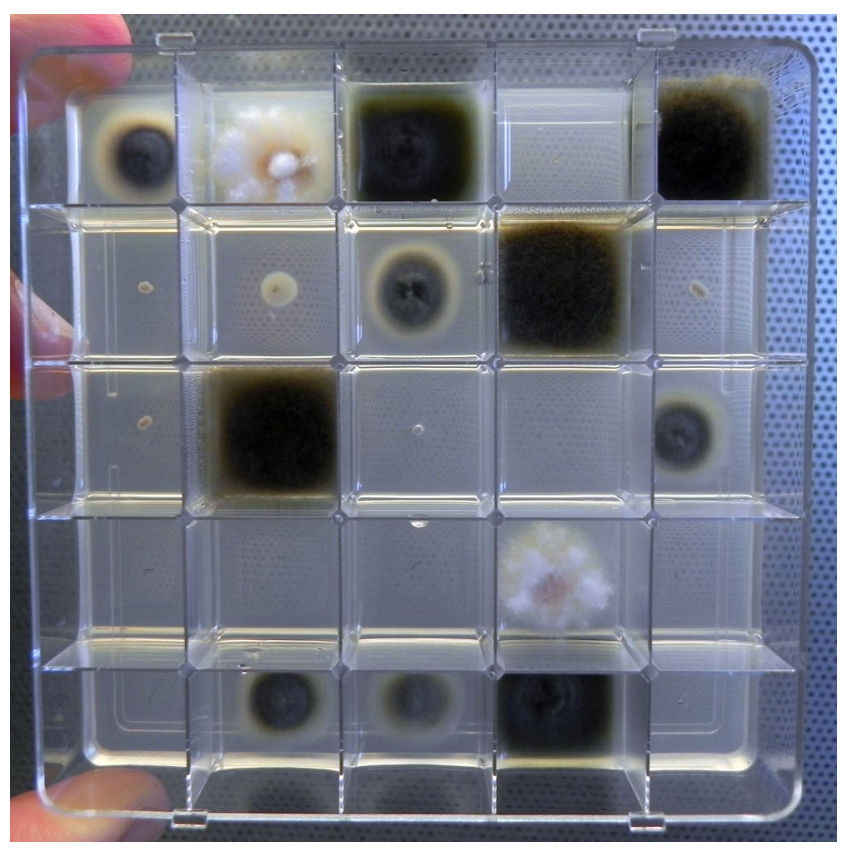

Fig. 7 Isolation of ericoid root mycobionts using 25-compartment Petri dishes. Short segments of surface-sterilized healthy-looking hair roots of Cassiope tetragona from a natural site in Longyearbyen (Svalbard) were plated on nutrient agar (MLA) and incubated for one month at $21^{\circ} \mathrm{C}$ in the dark, yielding 16 fungal isolates (i.e., $64 \%$ success ratio; note no contaminating sporulating fungi). Such an isolation setup has many advantages, for details, see the section "Root mycobiont isolation and maintenance of the obtained isolates" 
in the ericoid hair roots. Prolonged single-cell incubation could address this question better than plating of surfacesterilized root segments (see above).

Individual mycelia emerging from the hair root segments are transferred to new dishes (smaller plastic Petri dishes are more convenient in terms of medium consumption, handling, and storage) and taken care of as detailed below. It is advisable to keep the original isolation dishes and check them regularly, also because prolonged storage in a fridge of freshly isolated mycelia may lead to their sporulation (e.g., the first documented sporulation of H. bicolor, see Fig. 10e-n in Fehrer et al. 2019).

Any mycelial culture obtained from a surface-sterilized hair root segment could be a result of a growth competition among several mycobionts and therefore may be non-axenic (=contain more than one fungal strain). In the best case, such cultures are identified based on chimeric/mixed sequences (see below). They may be discarded or their individual components may be separated into axenic cultures by isolating single hyphal tips (Brown 1924b; Afanasiev 1937, also see Hildebrand 1938). When targeting specific ericoid root mycobionts, fungal competition can be to a certain degree reduced already at the sampling stage by focusing on specific host niches. For example, to my knowledge the only available serendipitoid isolate derived from ericoid roots was obtained from Vaccinium sp. growing on the top of a dead spruce stump, a niche apparently favoring recovery of basidiomycetous mycobionts (see Discussion in Vohník et al. 2016a). Analogously, for example, the recovery of the aquatic hyphomycetes that often colonize ericoid hair roots as possible endophytes (e.g., Bruzone et al. 2015 and 2017, also see Selosse et al. 2008) could be facilitated by submerged culturing, etc.

Besides the total number of the isolates obtained, it is advisable to evaluate the respective isolation success rate by stating the number/percentage of segments contaminated by fast-growing/sporulating fungi as well as those yielding no isolate.

\section{Maintenance of isolates}

Every obtained isolate should be labelled with a unique simple code independent of the isolate's current scientific name (cf. the turbulent taxonomy of $H$. hepaticicola) and kept as an actively growing pure culture until identified (see below). Selected isolates representing interesting or hitherto undescribed fungal taxa should be maintained for future investigations (physiological studies, resynthesis, taxonomic treatment, etc.) and ideally also deposited in a specialized publicly accessible international collection (e.g., the Westerdijk Fungal Biodiversity Institute, formerly Centraalbureau voor Schimmelcultures, www.wi.knaw.nl). Deposition of cultures is typically a free service. Private and even university collections typically cannot ensure that the deposited cultures will be readily available for interested researchers also after twenty, thirty or more years.

Two basic methods for isolate long term storage are agar slant cultures (i.e., keeping the isolates on slant agar based medium in vertically stored vials) and cultivation on agar media in Petri dishes. Compared to the cultivation in Petri dishes, agar slant cultures significantly save space and resources (especially when employing reusable glass vials), prevent inner water condensation (but easier go dry) and reduce the risk of infestation with mites. On the other hand, it is a more elaborate method which in my experience increases the chance of contamination during inoculation (especially when performed by less-experienced personnel) that is subsequently more difficult to recognize. After many years of keeping our isolates both as slant agars and in Petri dishes, I have moved the whole collection (a few hundred of isolates) to small plastic Petri dishes (6 cm in diameter), mainly because they are easier to prepare and inoculate, the colony morphology is easier to observe, and possible contaminations are easier to distinguish. Sub-cultivations take place every 9 to 12 months with practically no losses; dishes with new colonies of sufficient size are doublewrapped with an air permeable film, placed in clean plastic storage boxes of a suitable volume and stored in the dark in a fridge at ca. $6{ }^{\circ} \mathrm{C}$. It is not advisable to use the same space for storage of non-aseptic materials (fresh root samples with attached soil, non-sterile soil samples even when wrapped in plastic bags, etc.) because doing so may lead to the spread of, e.g., mites, which are strongly attracted by fungal odor and can bite through plastic wrappings and spread contaminating bacteria and fungi.

Complex low-sugar media such as MLA are more suitable for long-term maintenance of the isolates, and it is advisable to keep every isolate on at least two different media, switching then during each sub-cultivation (e.g., $\mathrm{PCA}=>\mathrm{MLA}=>\mathrm{PCA}=>\mathrm{MLA}$, etc.). Some other useful media are described in Chap. 3.2 in Repáč (2011), some alternative but less commonly used maintenance methods are described in Heinonen-Tanski and Holopainen (1991). It is extremely important to work aseptically because once the collection is contaminated or infested, it often results in a loss of many precious isolates. An even worse scenario is that contaminants spreading through the collection go unnoticed, and subsequently, they are used in inoculation experiments instead of the original (already suppressed) mycobionts.

\section{Isolate identification}

With the exception of $O$. maius, the common ericoid root mycobionts typically produce sterile (non-sporulating) mycelia that cannot be reasonably identified based only 
on appearance/morphology, growth rates, etc., that may dramatically change depending on culture conditions (type of the medium and its $\mathrm{pH}$, temperature, humidity, gas exchange, etc.) and age. On the other hand, the current relatively low costs of DNA sequencing facilitate identification of the obtained isolates using DNA barcoding (Hebert et al. 2003). A detailed description of the whole process is far beyond the scope and dimensions of this guide; hence, I will focus on a simple (and in a way intuitive) workflow that works well with the great majority of the ericoid mycobionts I have so far isolated. The listed software are freely available online, easy to use, and do not require significant computational power and using the command line.

\section{Things to consider}

1 Phylogenetically unrelated mycobionts may produce very similar (indistinguishable to the naked eye) mycelial colonies; hence, any kind of sorting the obtained isolates into groups according to appearance/macromorphology/ phenotype ("morphotyping") followed by identification of one "representative" isolate per each such group is strongly discouraged. If resources are limited, several isolates per each conservatively established morphotype must be identified to confirm ingroup conspecificity.

2 Many ericoid root mycobionts are unnamed and deserve taxonomic treatment, especially when represented by multiple isolates from different geographical and/ or host contexts (for interesting thoughts on what makes a species worth naming, see Seifert 2017, for an illustrative example of an ericoid mycobiont that had deserved to be named, see Midgley et al. 2018). However, describing a new fungal species is a nontrivial process that comprises detailed morphological characterization and photodocumentation, deposition of the holotype (a metabolically inactive (e.g., dried) culture) as well as culture ex-types and annotated sequences in reliable and publicly accessible repositories, ideally multi gene phylogenetic analyses, registration in MycoBank, etc. (see Seifert and Rossman (2010) who even offer a model manuscript for a new species description) and is best consulted with an experienced fungal taxonomist. This obviously applies also for species reclassifications-improper taxonomy leads to unnecessary confusion that may take years to resolve (e.g., the unnecessary inter-family transfer of the prominent ErMF from Rhizoscyphus to Pezoloma based solely on a morphological observation of a single apothecium, see Baral and Krieglsteiner 2006).

3 While culture-independent studies employing HTS typically produce thousands to millions of relatively short reads that must be bulk-processed by software, culture-dependent studies typically produce ca. 1-3 hundreds of metabolically active isolates yielding longer sequences that can be processed manually and subsequently used in reasonable phylogenetic analyses, species descriptions, etc.

4 The definite tool for identification of the obtained ericoid isolates at the species level is a phylogenetic analysis that includes appropriate reference sequences.

5 Only correctly annotated high-quality sequences should be deposited in the International Nucleotide Sequence Databases (INSD; Karsch-Mizrachi et al. 2018, https:// www.insdc.org/) to prevent confusion (see Nilsson et al. 2006 and 2012).

First, fresh mycelium of the isolate in question must be harvested, typically by dissecting a small piece of its colony growing on nutrient agar. It is advisable to limit the amount of the nutrient agar involved, e.g., by harvesting aerial mycelium, cultivating the colony on the surface of a cellophane membrane or in liquid culture, etc. Second, the total DNA must be isolated-a cheap but relatively timedemanding option is the modified sorbitol extraction method described in Štorchová et al. (2000), a very fast (under $30 \mathrm{~min}$ ) but expensive option is the REDExtract-N-Amp Plant Kit (Sigma-Aldrich) and similar that do not require special laboratory plastic/tools and liquid nitrogen and allow direct PCR without the need of prior DNA purification, which may come in handy when dealing with hundreds of fresh isolates. A time-saving option is to start with the latter and continue with the former in case of problematic isolates. The isolated DNA concentration and purity can be checked by various absorbance and fluorescent methods and this may come in handy when troubleshooting downstream PCR (e.g., see Boesenberg-Smith et al. (2012) who also offer a brief but informative overview of various DNA extraction methods).

Ericoid isolates are typically identified based on sequences of the ITS nuc-rDNA gene (the ITS1 + 5.8S + ITS2 region of the nuc-rDNA), but phylogenies of many fungal groups rather employ partial sequences of the large subunit nucrDNA gene (LSU) (see Porras-Alfaro et al. 2014) so where resources and time permit, it is advisable to amplify and sequence both these genes. They can be simultaneously amplified, e.g., by the V9G + LR8 primer pair (de Hoog and van den Ende 1998; Hopple and Vilgalys 1999) under the following PCR protocol: initial denaturation at $98{ }^{\circ} \mathrm{C}$ for $30 \mathrm{~s}, 40$ cycles of denaturation at $98^{\circ} \mathrm{C}$ for $10 \mathrm{~s}$, annealing at $62{ }^{\circ} \mathrm{C}$ for $30 \mathrm{~s}$, and elongation at $72{ }^{\circ} \mathrm{C}$ for $90 \mathrm{~s}$, and a final extension step at $72^{\circ} \mathrm{C}$ for $5 \mathrm{~min}$. The quality and length of PCR products can be checked by agarose gel electrophoresis and products yielding a single band of the desired length can be purified (some sequencing services offer PCR product purification prior to sequencing) and sent for sequencing (some sequencing services require that the PCR products are pre-mixed with the desired sequencing primer). When 
dealing with hundreds of isolates, the 96-well microplates save working time and space and typically also reduce costs of sequencing. Because the PCR product volume used for sequencing is relatively small, the same product can be used for sequencing of both the ITS and the partial LSU gene in both directions. Since some sequencing services offer prolonged sample storage, it is advisable to first order sequencing with one primer and then, depending on the quality of the obtained sequences, add additional sequencing order(s).

Sequences arrived, time to celebrate! Sequence chromatograms (especially the distal parts) must be checked for machine errors/quality and manually edited/trimmed and there are many software available to do so (e.g., Chromas (Technelysium) and FinchTV (Geospiza)). Sequences with low-quality/mixed signal must be discarded, and the respective isolates may be, e.g., challenged with other primers sets. However, even sequences with good quality chromatograms may still be problematic and Nilsson et al. (2012) provide basic guidelines for establishing whether they actually represent the desired gene, are given in the correct orientation, and do not represent chimeras. Sequences obtained using reverse primers must be converted to reverse complement sequences and aligned with the respective forward sequences, e.g., in Clustal W (Thompson et al. 1994) implemented in BioEdit (Hall 1999), yielding a consensus sequence (contig) that represents the respective fungal isolate.

There are several ways how to group isolates into molecular operational taxonomic units (MOTUs, see Floyd et al. 2002) based on similarity of their genes, including the analysis of restriction fragment length polymorphism (RFLP) performed after PCR but prior to sequencing (laborious and less precise but saved resources when costs of sequencing were considerably higher). When sequences of all (or a large majority of) isolates are available, one can attempt to align them in order to produce FASTA files with reasonably aligned sequences that further serve as matrices for MOTU delimitation by software, e.g., TOPALi (Biomathematiscs \& Statistics Scotland). The resulting number of MOTUs depends on the chosen phylogenetic analysis and its settings and the threshold limit for grouping. In general, lower limits serve for class/order/family assignment and higher for assignment at the genus/species level (for predicted threshold values for ITS and LSU of filamentous fungi see $\mathrm{Vu}$ et al. 2019). However, especially the ITS species threshold limit varies depending on the isolate taxonomic context (from 97 to $99 \%$ and more, see Garnica et al. 2016, also see Edgar 2018) and for certain fungal groups, the ITS gene (or even the whole nuc-rDNA) is not suitable for species delimitation at all (Grünig 2004; Gazis et al. 2011; Kolařík and Vohník 2018). Special attention should be paid to singletons (i.e., MOTUs containing only one sequence) as these may represent sequences with introns (cf. Perotto et al. 2000) or PCR artifacts (e.g., chimeric sequences often derived from non-axenic isolates, etc.).

Each delimited MOTU ideally represents a single species (at this point it is a good idea to get back to the isolates and check their phenotype diversity within individual MOTUs), and this may be checked by aligning all respective sequences to screen their heterogeneity, choosing the most divergent ones and compare these with publicly available sequences, e.g., using BLAST (Altschul et al. 1990) in GenBank at NCBI (Benson et al. 2013, https://www.ncbi.nlm.nih.gov/genbank) and in UNITE (Abarenkov et al. 2010, https://unite.ut.ee). In general, priority should be given to sequences derived from reliably identified cultures with deposited vouchers and the queries can be limited, e.g., to ITS or LSU sequences from fungal type and other reference material. Congruently, it is advisable to exclude environmental sequences as these may be taxonomically assigned (often by software) based on a top hit in the respective reference database that does not necessarily have the same taxonomy as the query sequence (Blaxter et al. 2005; Nilsson et al. 2012; Edgar 2018). Subsequently, the phylogenetic background of the sequence in question should be checked, e.g., by Blast Tree View (https://www.ncbi.nlm.nih.gov/blast/treev iew/treeView.cgi). When comparisons with type and other reference sequences are inconclusive at the species level, the "species hypothesis" concept (Kõljalg et al. 2013) in UNITE is available for an unambiguous alphanumeric assignment of the respective MOTU.

Representative sequence(s) of each delimited MOTU should be submitted to the INSD that include intuitive instructions on how to do it. Sequences should be annotated to the maximal level possible but at least the locality, country, date of isolation, source of the isolate (the host species name and its respective organ, e.g., surface-sterilized hair root, serially washed ectomycorrhiza, etc.) and reference (updated when the respective manuscript gets published) should be provided. Sequence labels/names should contain species names only if there are absolutely no doubts about such an assignment (cf. item 4 under "Things to consider" in the section "Isolate identification") and in agreement with the current taxonomy (for updated names and synonymy, including the anamorph-teleomorph relationships, see MycoBank). In the INSD, there are plethora of sequences labelled as if they originated from "ericoid mycorrhizal" or "endophytic" isolates in spite of the fact that this has rarely been rigorously tested (cf. item 3 under "Things to consider" in the section "Root mycobiont isolation and maintenance of the obtained isolates"); available nonmisleading alternatives include "ericoid root associated fungus" or simply "ericoid root mycobiont". 


\section{Resynthesis experiments}

Resynthesis experiments are necessary to fulfill Koch's postulates. In a simplified way (and as generally accepted), this means that to be assigned as mycorrhizal, the fungus in question must originate from a corresponding host (cf. paragraph 4 under the section "Theoretical background"), must be able to harmlessly colonize roots of a corresponding host (cf. item 4 under "Things to consider" in the section "Root mycobiont isolation and maintenance of the obtained isolates"), and must form the corresponding type of mycorrhiza (i.e., a dual root-fungus organ) possessing specific interfaces mediating the bi-directional nutrient transfer between the host plant (phytobiont) and its fungal partner (mycobiont), which is characteristic for the majority of mycorrhizal symbioses (i.e., specific functional associations between certain phytobionts and mycobionts). These interfaces are complex and specific structures (see Peterson and Massicotte 2004). It is generally accepted that they are formed only when the respective associations are indeed functional, i.e., the bi-directional nutritional transfer does take place between the phytobiont and the mycobiont (cf. Peterson et al. 2008). In other words, the presence of the AM arbuscules or the EcM Hartig net in a corresponding healthy host is commonly interpreted as a proof of the AM or EcM status of the mycobiont in question, respectively.

The situation is, however, more complicated in the case of the ErM symbiosis, which is morphologically recognized on the base of the "compact intracellular hyphal complexes" formed in the rhizodermis of the ericoid hair roots (Leake and Read 1991) that may turn out to be a rather subjective criterion (cf. item 2 under "Things to consider" in the section "Microscopic observations and photo-documentation"). Hence, some kind of "positive effects" of the established root-fungus association on the host plant (e.g., increased accumulation of biomass and/or nutrients) is often sought. However, biomass accumulation and/or nutrient uptake in ericoid plants can be simulated also by non-ErM fungi (e.g., the EcMF Cenococcum geophilum, see Vohník et al. 2007 and the saprobic basidiomycetous Agrocybe, see Vohník et al. 2012b) and therefore, one should always try to distinguish the "mycorrhizal" effects from the "any fungus present" effects, especially by establishing appropriate control treatments (see below).

In 2005, Hambleton and Sigler wrote that "standard (or optimal) conditions for ericoid mycorrhizal synthesis have not been established" and that "a thorough assessment of experimental conditions is needed to develop a more uniform protocol for ericoid mycorrhizal synthesis experiments". Looking back through these 15 years, one must conclude that very little has changed since then. Hence, the following text is an attempt to briefly describe and discuss various approaches to resynthesis experiments pertinent to the
ErM research. Much inspiration has been taken from the EcM research and interested readers are referred to the comprehensive overview of various resynthesis techniques by Peterson and Chakravarty (1991) who also discuss their pros and cons for particular studies as well as historical background.

\section{Things to consider}

1 Even fungi that do not form mycorrhizae in vitro might be mycorrhizal in nature. Conversely, fungi that do form intracellular hyphal coils in the rhizodermis of ericoid species in vitro may not necessarily form mycorrhizae in nature (Monreal et al. 1999, also see paragraph 9 under the section "Theoretical background" and item 2 under "Things to consider" in the section "Microscopic observations and photo-documentation").

2 The decision as to whether the mycobiont in question is an ErMF or not should be based on a series of experiments under contrasting conditions, not a single resynthesis attempt (cf. Vohník et al. 2012a and 2016a).

3 Ericoid mycorrhiza plays two fundamental ecophysiological roles, i.e., detoxification of the soil environment and acquisition of essential nutrients (primarily nitrogen) (Leake and Read 1991; Read and Kerley 1999; Perotto et al. 2002) and their relative importance may differ according to the respective environmental conditions (soil $\mathrm{pH}$, heavy metal availability and concentration, mineral nutrient availability and concentration, etc.). Both may lead to improved growth and/or nutrient uptake by the host plant.

4 Even non-symbiotic fungi may stimulate ericoid plant growth and/or nutrient uptake, e.g., by detoxification of the substrate, mineralization of organic matter, release of phytohormones or their analogues, elevation of $\left[\mathrm{CO}_{2}\right]$ in closed cultivation systems, etc. Such fungi may serve as positive non-ErM controls in resynthesis experiments.

5 The effects of ErMF on host plant growth and nutrient uptake may change in varying degrees with time"while overall impressions of the effect of specific treatments can be gained from inspection of the data over the whole experiment, comparisons made at single harvests can give different and conflicting results" (Stribley et al. 1975). Where possible, this "ontogenetic drift" should be accounted for because the practice of quoting the results from a single harvest only "may obscure changing relationships and unconsciously lead to erroneous conclusions, especially with regard to the frequently quoted percentage content of minerals" (Stribley et al. 1975).

6 Resynthesis protocols "should incorporate a reisolation/ identification step to ensure no external or cross 
contamination escapes detection" (Hambleton and Sigler 2005). At the same time, "sampling from untreated and surface-sterilized inoculated roots, as well as the surrounding soil medium, would also provide an assessment of the vigor and survival of the fungal partner used" (Hambleton and Sigler 2005).

No matter how obviously it sounds, before setting up a resynthesis experiment, one should firstly decide what is the main aim/hypothesis and how it is to be achieved/ tested, including appropriate control/reference treatments. For example, when testing a hypothetic ErM status of a newly isolated mycobiont, its performance should ideally be investigated in a series of in vitro experiments employing several different cultivation substrates and compared to at least one true ErMF and at least one nonErM non-pathogenic fungus (e.g., some common EcMF or a soil saprobe not harmful to ericoid plants).

While designing an in vitro experiment, one must decide about (1) type of the plant material, (2) cultivation vessels, (3) cultivation substrate, (4) way of inoculation, (5) placement of the experiment (ambient conditions), (6) its time span, and (7) harvest workflow.

Ad (1): While the main advantage of tissue culturederived rooted microcuttings is their genetic uniformity, the disadvantages include limited availability (typical Northern Hemisphere wild species like C. vulgaris, Erica carnea, and Vaccinium myrtillus are practically unavailable as tissue cultures) and price, sometimes also problems with rooting/root development. In contrast, seeds can be easily collected in nature and stored for prolonged time in a fridge so that seedlings can be readily produced in large quantities and selected according to size, age/ developmental stage, etc.

Example: Ripe undamaged European blueberry ( $V$. myrtillus) fruits are collected in nature when available, dried at room temperature for a few days and stored in a fridge at ca. $6{ }^{\circ} \mathrm{C}$ (when properly stored, the seeds remain viable for up to 2 years). Before the outset of an experiment, they are re-hydrated in tap water for a few days at room temperature, the seeds are handpicked from the fruits, surface-sterilized (see the section "Root mycobiont isolation and maintenance of the obtained isolates") and inserted a few mm into solidified modified MMN (i.e., without maltose and with $1 / 10$ concentration of glucose, amended with antibiotics to prevent the growth of bacteria) in square plastic 25-compartment Petri dishes (Fig. 8). The dishes are wrapped with an air permeable foil/tape and incubated in a growth chamber in the shade until the seeds start to geminate (usually after ca. $4-6$ weeks under the $21 / 16{ }^{\circ} \mathrm{C}$ day/night regime). Seedlings are gradually acclimatized to full irradiation and used for the resynthesis experiment when having ca. 5-7 leaves.
Ad (2): The choice is wide and includes, e.g., glass or plastic Petri dishes of various sizes and shapes, glass or plastic test tubes of various lengths and diameters, household jars of various volumes or specialized autoclavable plasticware used for plant tissue cultures. From the physiological point of view, one must consider especially the material permeability for photosynthetically active radiation (PAR), sufficient space for the development of both the phytobiont and the mycobiont, unrestricted gas exchange (to prevent accumulation of $\mathrm{CO}_{2}$, volatile agents like ethylene, etc.) and the rate of desiccation (e.g., see Tables 1-3 in Fal et al. 2002, also see Huang and Chen 2005). From the practical point of view, factors like easy assembly/setup, inoculation and access to the plants at harvest, the space occupied in the growth chamber and reusability/price typically influence the final decision.

Example: Plastic Petri dishes are non-autoclavable but typically sold sterile; they are affordable, lightweight, space-efficient (when used in inclined/vertical position) and their thin walls are well permeable for PAR. Square plastic Petri dishes $(12 \times 12 \mathrm{~cm})$ provide sufficient inner space for most ericoid species seedlings even after prolonged cultivation (Fig. 9) and can be efficiently used for the papersandwich resynthesis technique (see Chilvers et al. 1986). Split plastic Petri dishes $(9 \mathrm{~cm}$ in diameter) are a good alternative, especially after perforating the central septum to accommodate the seedling's shoot (see Figs. 1-5 in Vohník et al. 2005). The Magenta GA-7 cultivation vessels

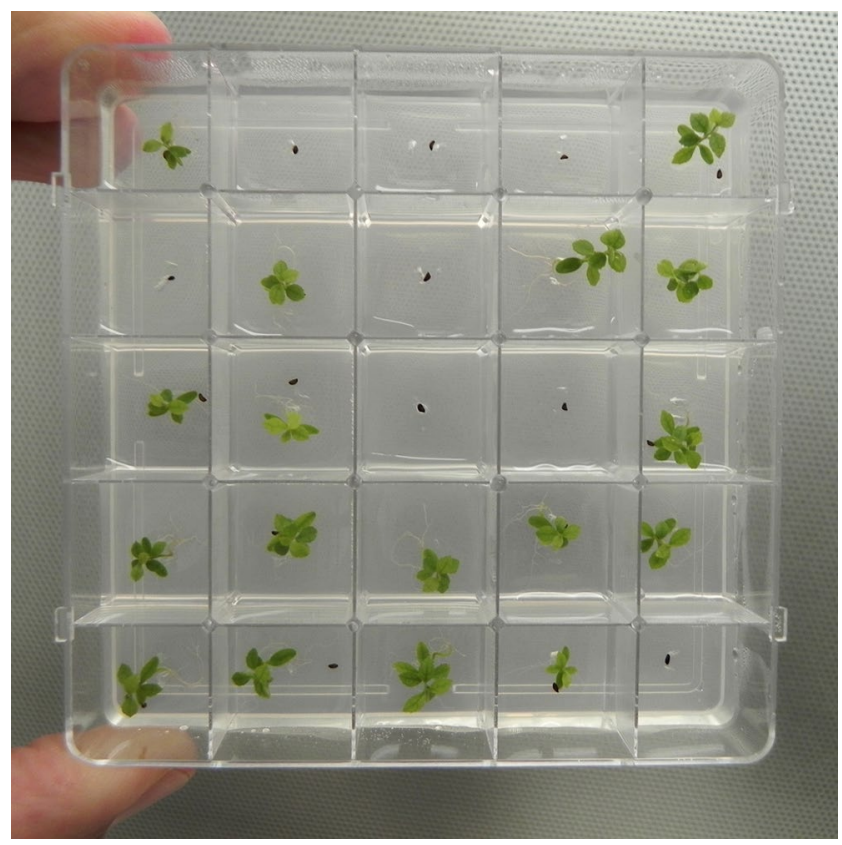

Fig. 8 Producing ericoid seedlings for resynthesis experiments. European blueberry (Vaccinium myrtillus) seedlings after ca. three months of cultivation in 25-compartment Petri dishes 
(Sigma-Aldrich) are autoclavable, lightweight, spaceefficient and well permeable for PAR; with lids in the highest position, they offer reasonable gas exchange (see Table 1 in Huang and Chen 2005) and wrapping the lids with an air permeable foil/tape significantly reduces their otherwise relatively high desiccation rate/chance of contamination.

Ad (3): The main advantage of the synthetic media/ substrates like MMN is reproducibility. On the other hand, one of the three requirements suggested by Leake and Read (1991) is that "the fungus must be grown with its putative host plant under semi-natural conditions, i.e. on an ecologically meaningful substrate without the addition of exogenous carbon supplies" and this is typically mimicked by mixtures of peat with various inert materials like agar, perlite, quartz sand, etc. The characteristics of an "ecologically meaningful substrate" obviously depend on the ecological/geographic context of the study (cf. Fig. 1). Needless to say, the cultivation substrate must be sterile. This is commonly achieved by autoclaving that may, however, significantly alter certain substrate properties. For example, peat typically releases compounds phytotoxic to ericoid seedlings (Stribley et al. 1975), which may be to a certain degree neutralized by active charcoal (Duclos and Fortin 1983; Leake and Read 1991). Gamma rays sterilization represents a less damaging alternative that is, however, more expensive and typically not readily available.

Example: Peat is passed through a $3 \mathrm{~mm}$ sieve, mixed 1: 1 (v/v) with perlite, moistened with tap water and autoclaved 2-times after $24 \mathrm{~h}\left(60 \mathrm{~min}\right.$ at $\left.121^{\circ} \mathrm{C}\right)$. The autoclaved substrate is confirmed sterile by plating on nutrient agar. The desired volume of the substrate is placed in the lower part of each square $12 \times 12 \mathrm{~cm}$ plastic Petri dish and molten $0.8 \%$ water agar amended with $0.1 \%$ activated charcoal is pipetted over its surface. Alternatively, the desired volume of unsterile substrate and the molten water agar + activated charcoal can be placed in Magenta GA-7 vessels and autoclaved as above.

Ad (4): Small plugs overgrown with mycelium dissected from fresh cultures in Petri dishes are easy to obtain and will do in most in vitro schemes. Their main disadvantage is that they introduce nutrients into the cultivation system; this can be reduced by a suitable choice of the cultivation medium, preferably low in simple sugars, and by introducing plugs without mycelium to control treatments. Alternatively, the mycelium can be pre-cultivated on an inert carrier (e.g., pieces of nylon mesh) or on pieces of filter paper/thin cardboard (see Chilvers et al. 1986).

Example: Mycobiont cultures are pre-cultivated in the dark at room temperature ideally on the same medium as the seedlings until they produce the desired amount of mycelium. Small plugs (ca. $3 \mathrm{~mm}$ in diam.) are dissected from the margins of the actively growing colonies, placed on the surface of the sterile amended cultivation substrate in Magenta GA-7 vessels (see above), incubated in the dark at room temperature and the growth of new mycelium is periodically checked (Fig. 10a). Control vessels are inoculated with plugs without mycelium that also serve for double-checking sterility of the substrate. When covering most of the substrate's surface (Fig. 10b), the new mycelium is mixed into the substrate, the seedlings are introduced and watered with sterile water, the lids are secured in the highest position (see the marks at the vessels) for optimal gas exchange and wrapped with an air permeable foil/tape (for a comparative study on the performance of the widely used Parafilm (Sigma-Aldrich), see Xu et al. (2019)). If Petri dishes are employed, the substrate can be covered with
Fig. 9 Resynthesis with European blueberry cultivated in square Petri dishes. European blueberry (Vaccinium myrtillus) seedlings were aseptically cultivated for a few months in a peatperlite substrate amended with water agar containing $0.1 \%$ activated charcoal (see the section "Resynthesis experiments") and inoculated with the typical ErMF Hyaloscypha hepaticicola (a). To display the development of the extraradical mycelium (arrows), a sheet of sterile filter paper (asterisk) was removed from the surface of the substrate prior taking the photo (b)
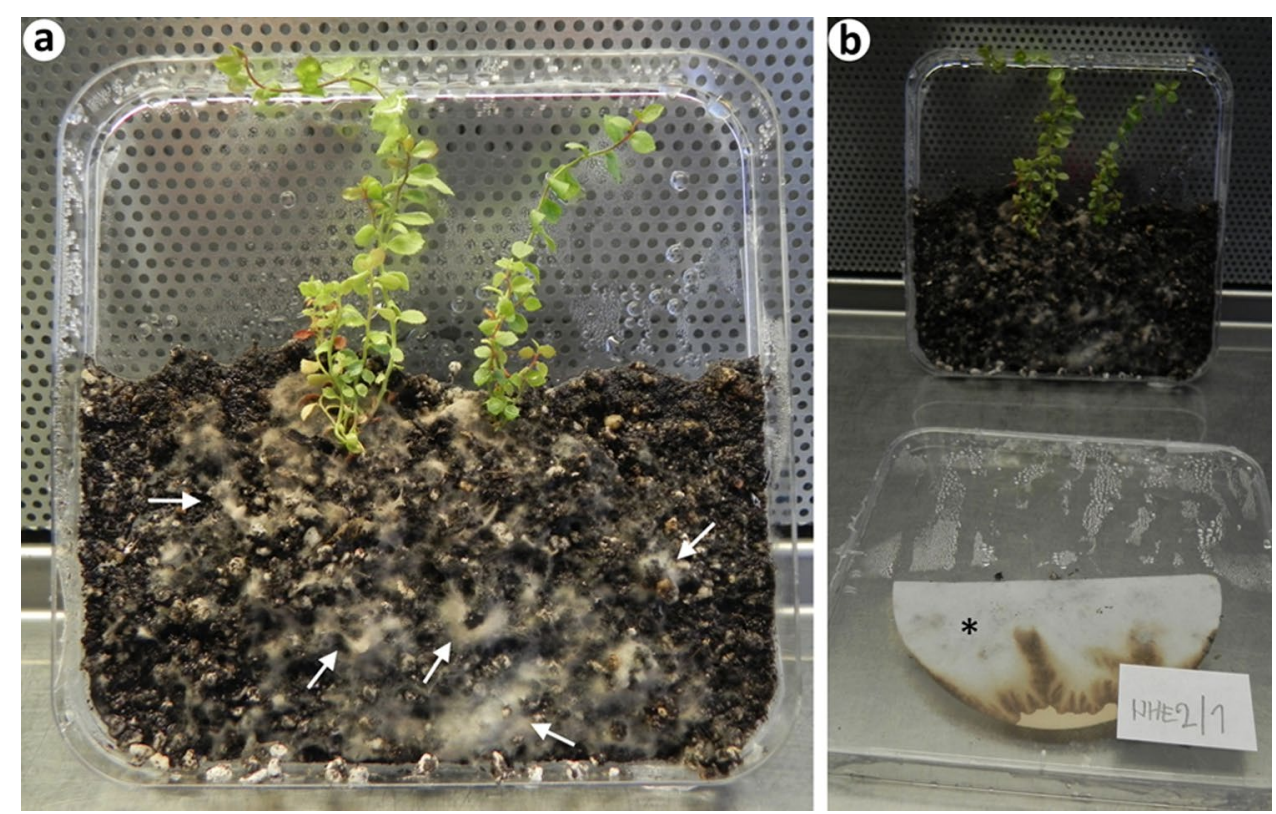
Fig. 10 Inoculation of a peat-perlite substrate with agar plugs containing fungal mycelium. a New mycelium of the typical ErMF Hyaloscypha hepaticicola emerging from agar plugs after ca. 2 weeks of incubation at room temperature in the dark. b H. hepaticicola mycelium covering most of the surface is ready to be mixed into the substrate (see the section "Resynthesis experiments")

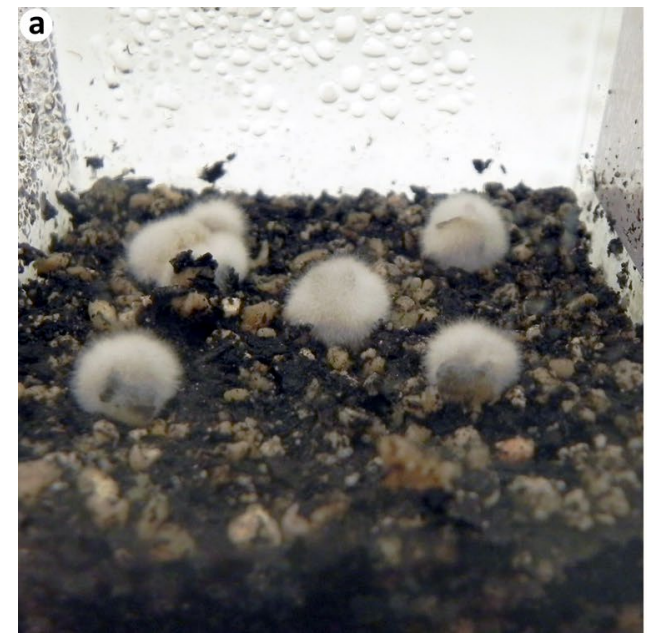

b

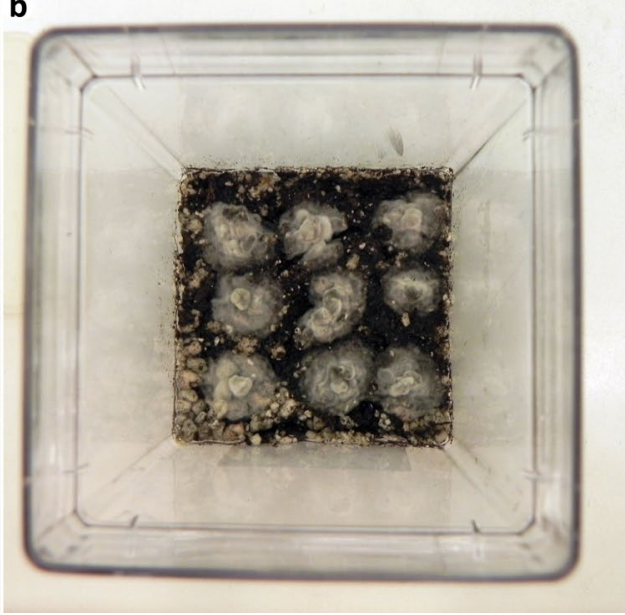

sterile filter paper to prevent roots from growing into the substrate. The plugs are placed on the paper and when fresh mycelium is produced, the seedling are introduced in a way that their roots are placed over the mycelium and covered with another sterile filter paper.

Ad (5): An appropriate cultivation environment must, above all, provide a sufficient amount of evenly distributed PAR, a defined temperature and a reasonable protection against contamination/infestation (e.g., by collembolans and mites). To my knowledge, an optimal amount of PAR necessary for proper functioning of ericoid mycorrhiza has not been rigorously established but undoubtedly varies depending on different phytobiont vs. mycobiont combinations, their ontogenetic stages and ecotypes, substrate types, ambient conditions, etc. While many ericoid species like European blueberry thrive on the forest floor and actually do not need much light, others like heather $(C$. vulgaris) or lingonberry (Vaccinium vitis-idaea) prosper in full sun (=heliophytes) and their light requirements in resynthesis experiments may be correspondingly higher. Similar holds true for the temperature requirements that will certainly significantly differ, e.g., between Neotropical epiphytic and arctic ericoid species. In any case, it is advisable to respect natural diurnal cycles of light and temperature by maintaining an appropriate day/night regime.

Ad (6): First signs of intracellular hyphal colonization by $H$. hepaticicola typical for ericoid mycorrhiza are visible after ca. 3-4 weeks from inoculation and the colonization levels peak ca. 6 weeks after inoculation (Duddridge and Read 1982; McLean et al. 1998). The former seems to hold true also for the serendipitoid fungi though the progress of the colonization may be slower (Vohník et al. 2016a). The functional life span of the ErM rhizodermal cells seems to be relatively short (Smith and Read 2008a) as evidence of degradation of the host cell cytoplasm may be detected already after ca. 7-8 weeks from inoculation (Duddridge and Read 1982). Hence, with respect to the colonization development, the minimal time frame of 1.5-2 months is recommended for resynthesis experiments with ericoid plants and their mycobionts.

Ad (7): At the time of harvest, a few small pieces of the substrate from each experimental vessel should be plated on a nutrient medium and incubated in the dark at room temperature until producing mycelium. Plating of pieces of non-inoculated (control) substrate serves to confirm its sterility at the end of the experiment. The mycelia are identified as outlined in the section "Isolate identification" and must be identical with the inoculated mycobionts (cf. item 6 under "Things to consider" in the section "Resynthesis experiments").

Example: Plants are removed from the cultivation vessels, and their roots are separated from shoots and processed as outlined in the sections "Root sample collection and handling" and "Microscopic observations and photodocumentation". Representative root segments can be handled as outlined in item 6 under "Things to consider" in the section "Resynthesis experiments". Shoots are dried and weighed and if conditions permit, their elemental composition is analyzed. The gathered data are statistically analyzed and the colonization patterns (see paragraph 9 under the section "Theoretical background" and item 2 under "Things to consider" in the section "Microscopic observations and photo-documentation") and growth responses (see items 1-4 under "Things to consider" in the section "Resynthesis experiments", and Fig. 11) are conservatively interpreted.

\section{Conclusions-what it takes to assign a mycobiont as "ericoid mycorrhizal"?}

In 1991, Leake and Read wrote that "the isolation and culturing of a fungus and the demonstration that it forms typical 'structures' is only the first stage in the determination 


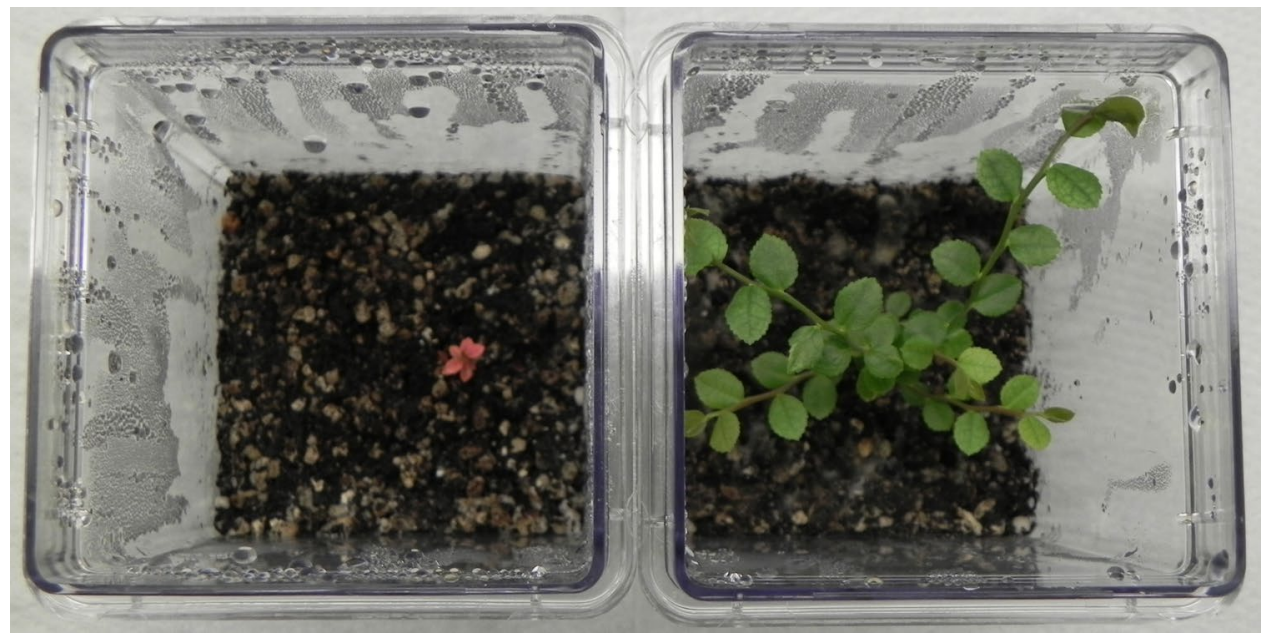

Fig. 11 Resynthesis with European blueberry cultivated in Magenta GA-7 vessels. European blueberry (Vaccinium myrtillus) seedlings were aseptically cultivated for a few months in a peatperlite substrate amended with water agar containing $0.1 \%$ activated charcoal (see the section "Resynthesis experiments") and either left non-inoculated (left) or inoculated with a strain of the typical ErMF Hyaloscypha hepaticicola (right). Such a tremendous difference in growth may be mainly due to (1) substrate detoxification, (2) mineralization of the organically-bound nutrients in the rhizosphere,

of the nature of the relationship between heterotroph and autotroph" and that "since many fungi have the ability to invade roots, evidence that under conditions approaching those prevailing in nature the relationship between host and fungus is of a mutualistic kind is required before the association can legitimately be described as being mycorrhizal". Looking back through these ca. 30 years, one tends to conclude that most ErM studies did not go beyond this "first stage".

Leake and Read (1991) also proposed three requirements that "must be met before any root-fungus association can be described as being mycorrhizal" and in the case of ericoid mycorrhiza, the second part of the third one is indisputably the most intricate (in italics): "There must be experimental evidence that infection by the fungus leads to enhancement of growth or nutrient capture by the host, and knowledge of the extent of the 'dependence' of the heterotroph upon its host for carbon supplies should be obtained". However, considering their well-known saprobic capabilities, why should fungi like $H$. hepaticicola, $K$. argillacea and $O$. maius depend on the carbon supplied by their host plants? Indeed, "the ErMF gene repertoire reveals a capacity for a dual saprotrophic and biotrophic lifestyle" that may "reflect an incomplete transition from saprotrophy to the mycorrhizal habit, or a versatile life strategy similar to fungal endophytes" (Martino et al. 2018). Perhaps most of ErMF, and especially $K$. argillacea and $O$. maius, are in fact "facultatively" ericoid mycorrhizal? If so, are there
(3) phytohormone release, or (4) mycorrhizal transport of nutrients to the host plant by the ErMF, or a combination of these effects (see item 3 under "Things to consider" in the section "Resynthesis experiments"). Since under natural conditions no plants grow without contacts with soil fungi and some non-mycorrhizal fungi may exhibit effects similar to ErMF, a proper selection of control treatments (see item 4 under "Things to consider" in the section "Resynthesis experiments") is necessary

any "obligate" ErMF? Perhaps the difficult-to-cultivate serendipitoid fungi? Is ericoid mycorrhiza in fact "another example of controlled parasitism of a fungal partner by the host plant, similar to the type that occurs with orchids" (Rice and Currah 2006)? Sequencing of the genome of the available Ericaceae-derived serendipitoid isolate (see Vohník et al. 2016a) may shed new light on these issues.

Returning to the primary scope of this simplified guide, it is obvious that any assignment of a mycobiont derived from ericoid roots as a new ErMF should be approached with utmost caution. On the other hand, when some mycobiont is regularly isolated from ErM roots, repeatedly forms fine compact intracellular hyphal coils in the living rhizodermal cells of ericoid hosts and repeatedly enhances their growth and/or nutrient uptake, why not calling it, e.g., an ericoid root-associated beneficial mycobiont, until a reasonable proof of mutualism (that in fact does not need to be connected with the mycobiont carbon dependency on the phytobiont) is available?

Acknowledgements I wish to thank Paula A. Buil Maldonado for her endless patience and understanding as well as the careful revisions of earlier versions of this paper, Martina Réblová for the useful advices on several methods included in this review, Ondřej Borovec for preparing the paraffin thin sections, and the two anonymous reviewers and Jan Colpaert (editor) for their valuable comments and suggestions. The first draft of this paper was finished during the SARS-CoV-2 lockdown in Córdoba, Argentina, and I sincerely thank my amazing hosts, Ms. Nora E. Maldonado Maldonado and Mr. Raúl Á. Buil Roig, for their exceptional kindness and hospitality (¡muchas gracias, papis!). 
Funding This work was supported by the Czech Science Foundation (GAČR 18-05886S) and the Institute of Botany, Czech Academy of Sciences (RVO 67985939)

\section{References}

Abarenkov K, Nilsson RH, Larsson K-H et al. (2010) The UNITE database for molecular identification of fungi - recent updates and future perspectives. New Phytol 186:281-285

Afanasiev MM (1937) Method of isolating single hyphal tips of Actinomyces. Phytopathology 27:1182-1183

Agerer R, Ammirati J, Blanz P et al. (2000) Always deposit vouchers. Mycol Res 104:642-644

Allen TR, Millar T, Berch SM, Berbee ML (2003) Culturing and direct DNA extraction find different fungi from the same ericoid mycorrhizal roots. New Phytol 160:255-272

Altschul SF, Gish W, Miller W, Myers EW, Lipman DJ (1990) Basic local alignment search tool. J Mol Biol 215:403-410

Baral H-O, Krieglsteiner L (2006) Hymenoscyphus subcarneus, a little known bryicolous discomycete found in the Bialowieza National Park. Acta Mycol 41:11-20

Benson DA, Cavanaugh M, Clark K et al. (2013) GenBank. Nucleic Acids Res 41:D36-D42

Boesenberg-Smith KA, Pessarakli MM, Wolk DM (2012) Assessment of DNA yield and purity: an overlooked detail of PCR troubleshooting. Clin Microbiol News1 34:3-6

Bonfante-Fasolo P, Gianinazzi-Pearson V (1979) Ultrastructural aspects of endomycorrhiza in the Ericaceae I: Naturally infected hair roots of Calluna vulgaris. New Phytol 83:739-744

Brown W (1924a) Two mycological methods. I. A simple method of freeing fungal cultures from bacteria. Ann Bot 38:401-402

Brown W (1924b) Two mycological methods. II. A method of isolating single strains of fungi by cutting out a hyphal tip. Ann Bot 38:402-404

Brundrett M, Bougher N, Dell B, Grove T, Malajczuk N (1996) Working with mycorrhizas in forestry and agriculture. Australian Centre for International Agricultural Research, Canberra

Bruzone MC, Fontenla SB, Vohník M (2015) Is the prominent ericoid mycorrhizal fungus Rhizoscyphus ericae absent in the Southern Hemisphere's Ericaceae? A case study on the diversity of root mycobionts in Gaultheria spp. from northwest Patagonia, Argentina. Mycorrhiza 25:25-40

Bruzone MC, Fehrer J, Fontenla SB, Vohník M (2017) First record of Rhizoscyphus ericae in Southern Hemisphere's Ericaceae. Mycorrhiza 27:147-163

Cairney JWG, Ashford AE (2002) Biology of mycorrhizal associations of epacrids (Ericaceae). New Phytol 154:305-326

Cairney JWG, Meharg AA (2003) Ericoid mycorrhiza: a partnership that exploits harsh edaphic conditions. Eur J Soil Sci 54:735-740

Chilvers GA, Douglass PA, Lapeyrie FF (1986) A paper-sandwich technique for rapid synthesis of ectomycorrhiza. New Phytol 103:397-402

Dalpé Y (1986) Axenic synthesis of ericoid mycorrhiza in Vaccinium angustifolium Ait. by Oidiodendron species. New Phytol 103:391-396

de Hoog GS, van den Ende AHGG (1998) Molecular diagnostics of clinical strains of filamentous Basidiomycetes. Mycoses 41:183-189

Dighton J, Coleman DC (1992) Phosphorus relations of roots and mycorrhizas of Rhododendron maximum L. in the southern Appalachians, North Carolina. Mycorrhiza 1:175-184

Donachie SP, Foster JS, Brown MV (2007) Culture clash: challenging the dogma of microbial diversity. ISME J 1:97-102
Duckett JG, Read DJ (1995) Ericoid mycorrhizas and rhizoidascomycete associations in liverworts share the same mycobiont: isolation of the partners and resynthesis of the associations in vitro. New Phytol 129:439-447

Duclos JL, Fortin JA (1983) Effect of glucose and active charcoal on in vitro synthesis of ericoid mycorrhiza with Vaccinium spp. New Phytol 94:95-102

Duddridge J, Read DJ (1982) An ultrastructural analysis of the development of mycorrhizas in Rhododendron ponticum. Can J Bot 60:2345-2356

Edgar RC (2018) Accuracy of taxonomy prediction for 16S rRNA and fungal ITS sequences. PeerJ 6:e4652

Egger KN, Sigler L (1993) Relatedness of the ericoid endophytes Scytalidium vaccinii and Hymenoscyphus ericae inferred from analysis of ribosomal DNA. Mycologia 85:219-230

Fal MA, Majada MP, Sánchez Tamés R (2002) Physical environment in non-ventilated culture vessels affects in vitro growth and morphogenesis of several cultivars of Dianthus caryophyllus L. In Vitro Cell Dev Biol-Plant 38:589-594

Fehrer J, Réblová M, Bambasová V, Vohník M (2019) The rootsymbiotic Rhizoscyphus ericae aggregate and Hyaloscypha (Leotiomycetes) are congeneric: Phylogenetic and experimental evidence. Stud Mycol 92:195-225

Floyd R, Abebe E, Papert A, Blaxter M (2002) Molecular barcodes for soil nematode identification. Mol Ecol 11:839-850

Foster ZSL, Weiland JE, Scagel CF, Grünwald NJ (2020) The composition of the fungal and oomycete microbiome of Rhododendron roots under varying growth conditions, nurseries, and cultivars. Phytobiomes J 4:156-164

Freudenstein JV, Broe MB, Feldenkris ER (2016) Phylogenetic relationships at the base of Ericaceae: Implications for vegetative and mycorrhizal evolution. Taxon 65:794-804

Fraymouth J (1956) Haustoria of the Peronosporales. Trans Brit Mycol Soc 39:79-107

Fujimura KE, Egger KN (2012) Host plant and environment influence community assembly of High Arctic root-associated fungal communities. Fungal Ecol 5:409-418

Gams W, Hoekstra ES, Aptroot A (1998) CBS Course of Mycology, 4 th edn. Centraalbureau voor Schimmelcultures, Baarn

Garnica S, Schön MA, Abarenkov K et al. (2016) Determining threshold values for barcoding fungi: lessons from Cortinarius (Basidiomycota), a highly diverse and widespread ectomycorrhizal genus. FEMS Microbiol Ecol 92:fiw045

Gazis R, Rehner S, Chaverri P (2011) Species delimitation in fungal endophyte diversity studies and its implications in ecological and biogeographic inferences. Mol Ecol 20:3001-3013

Gemma JN, Koske RE (1990) Mycorrhizae in recent volcanic substrates in Hawaii. Amer J Bot 77:1193-1200

Giovannetti M, Mosse B (1980) An evaluation of techniques for measuring vesicular-arbuscular infection in roots. New Phytol 84:489-500

Goulart BL, Schroeder ML, Demchak K et al (1993) Blueberry mycorrhizae: current knowledge and future directions. Acta Hortic 346:230-239

Grelet GA, Johnson D, Paterson E, Anderson IC, Alexander IJ (2009) Reciprocal carbon and nitrogen transfer between an ericaceous dwarf shrub and fungi isolated from Piceirhiza bicolorata ectomycorrhizas. New Phytol 182:359-366

Grelet G, Martino E, Dickie IA, Tajuddin R, Artz R (2016) Ecology of ericoid mycorrhizal fungi: What insight have we gained with molecular tools and what's missing? In: Martin FM (ed) Molecular mycorrhizal symbiosis. John Wiley \& Sons, Hoboken

Grunewaldt-Stöcker G, von den Berg C, Knopp J, von Alten H (2013) Interactions of ericoid mycorrhizal fungi and root pathogens in Rhododendron: In vitro tests with plantlets in sterile liquid culture. Plant Root 7:33-48 
Grunewaldt-Stöcker G, von Alten H (2016) Is the root-colonizing endophyte Acremonium strictum an ericoid mycorrhizal fungus? Mycorrhiza 26:429-440

Grünig CR (2004) Population biology of the tree-root endophyte Phialocephala fortinii. Doctoral dissertation. Swiss Federal Institute of Technology, Zürich

Grünig CR, Brunner PC, Duò A, Sieber TN (2007) Suitability of methods for species recognition in the Phialocephala fortiniiAcephala applanata species complex using DNA analysis. Fungal Genet Biol 44:773-788

Grünig CR, Queloz V, Sieber T, Holdenrieder O (2008) Dark septate endophytes (DSE) of the Phialocephala fortinii s. 1.-Acephala applanata species complex in tree roots: classification, population biology, and ecology. Botany 86:1355-1369

Hall TA (1999) BioEdit: a user-friendly biological sequence alignment editor and analysis program for Windows 95/98/ NT. Nucleic Acids Symp Ser 41:95-98

Hallmann J, Berg G, Schulz B (2006) Isolation procedures for endophytic microorganisms. In: Schulz BJE, Boyle CJC, Sieber TN (eds) Microbial root endophytes. Springer Verlag, Berlin Heidelberg, pp 299-319

Hamim A, Miché L, Douaik A et al. (2017) Diversity of fungal assemblages in roots of Ericaceae in two Mediterranean contrasting ecosystems. C R Biol 340:226-237

Harley JL (1959) The biology of mycorrhiza. Leonard Hill, London

Hebert PDN, Cywinska A, Ball SL, deWaard JR (2003) Biological identifications through DNA barcodes. Proc R Soc London [Biol] 270:313-321

Heinonen-Tanski H, Holopainen T (1991) Maintenance of ectomycorrhizal fungi. In: Norris JR, Read DJ, Varma AK (eds) Techniques for the study of mycorrhiza. Method Microbiol 23:413-422

Hopple JS, Vilgalys R (1999) Phylogenetic relationships in the mushroom genus Coprinus and dark-spored allies based on sequence data from the nuclear gene coding for the large ribosomal subunit RNA: divergent domains, outgroups, and monophyly. Mol Phylogenet Evol 13:1-19

Huang C, Chen C (2005) Physical properties of culture vessels for plant tissue culture. Biosyst Eng 91:501-511

Karsch-Mizrachi I, Nakamura Y, Cochrane G et al. (2018) The International Nucleotide Sequence Database Collaboration. Nucleic Acids Res 46:D48-D51

Knapp DG, Németh JB, Barry K et al. (2018) Comparative genomics provides insights into the lifestyle and reveals functional heterogeneity of dark septate endophytic fungi. Sci Rep 8:6321

Kohn LM, Stasovski E (1990) The mycorrhizal status of plants at Alexandra Fiord, Ellesmere Island, Canada, a High Arctic site. Mycologia 82:23-35

Kohout P, Sýkorová Z, Bahram M et al. (2011) Ericaceous dwarf shrubs affect ectomycorrhizal fungal community of the invasive Pinus strobus and native Pinus sylvestris in a pot experiment. Mycorrhiza 21:403-412

Kolařík M, Vohník M (2018) When the ribosomal DNA does not tell the truth: The case of the taxonomic position of Kurtia argillacea, an ericoid mycorrhizal fungus residing among Hymenochaetales. Fungal Biol 122:1-18

Kõljalg U, Nilsson RH, Abarenkov K et al. (2013) Towards a unified paradigm for sequence-based identification of fungi. Mol Ecol 22:5271-5277

Koske RE, Gemma JN, Englander L (1990) Vesicular-arbuscular mycorrhizae in Hawaiian Ericales. Amer J Bot 77:64-68

Kowal J, Pressel S, Duckett JG, Bidartondo MI, Field KJ (2018) From rhizoids to roots? Experimental evidence of mutualism between liverworts"and ascomycete fungi. Ann Bot 121:221-227
Kron KA, Judd WS, Stevens PF et al. (2002) Phylogenetic classification of Ericaceae: Molecular and morphological evidence. Bot Rev 68:335-423

Kron KA, Luteyn JL (2005) Origins and biogeographic patterns in Ericaceae: New insights from recent phylogenetic analyses. Biol Skr 55:479-500

Largent DL, Sugihara N, Wishner C (1980) Occurrence of mycorrhizae on ericaceous and pyrolaceous plants in northern California. Can J Bot 58:2274-2279

Leake JR, Read DJ (1991) Experiments with ericoid mycorrhiza. In: Norris JR, Read DJ, Varma AK (eds) Techniques for the study of mycorrhiza. Method Microbiol 23:435-459

Lorberau KE, Botnen SS, Mundra S et al. (2017) Does warming by open-top chambers induce change in the root-associated fungal community of the arctic dwarf shrub Cassiope tetragona (Ericaceae)? Mycorrhiza 27:513-524

Lukešová T, Kohout P, Větrovský T, Vohník M (2015) The potential of Dark Septate Endophytes to form root symbioses with ectomycorrhizal and ericoid mycorrhizal middle European forest plants. PLoS ONE 10:e0124752

Luteyn JL (2002) Diversity, adaptation, and endemism in Neotropical Ericaceae: biogeographical patterns in the Vaccinieae. Bot Rev 68:55-87

Malloch D (1981) Moulds: their isolation, cultivation and identification. University of Toronto Press, Toronto

Martino E, Morin E, Grelet G-A et al. (2018) Comparative genomics and transcriptomics depict ericoid mycorrhizal fungi as versatile saprotrophs and plant mutualists. New Phytol 217:1213-1229

Marx DH (1969) Influence of ectotrophic mycorrhizal fungi on resistance of pine roots to pathogenic infections I. Antagonism of mycorrhizal fungi to root pathogenic fungi and soil bacteria. Phytopathology 59:153-163

Massicotte HB, Melville LH, Peterson RL (2005) Structural characteristics of root-fungal interactions for five ericaceous species in eastern Canada. Can J Bot 83:1057-1064

McGonigle TP, Miller MH, Evans DG, Fairchild GL, Swan JA (1990) A new method which gives an objective measure of colonization of roots by vesicular-arbuscular mycorrhizal fungi. New Phytol 115:495-501

McLean CB, Lawrie AC (1996) Patterns of root colonization in Epacridaceous plants collected from different sites. Ann Bot 77:405-411

McLean CB, Anthony J, Collins RA, Steinke E, Lawrie AC (1998) First synthesis of ericoid mycorrhizas in the Epacridaceae under axenic conditions. New Phytol 139:589-593

Midgley DJ, Chambers SM, Cairney JWG (2002) Spatial distribution of fungal endophyte genotypes in a Woollsia pungens (Ericaceae) root system. Aust J Bot 50:559-565

Midgley DJ, Chambers SM, Cairney JWG (2004) Distribution of ericoid mycorrhizal endophytes and root-associated fungi in neighbouring Ericaceae plants in the field. Plant Soil 259:137-151

Midgley DJ, Rosewarne CP, Greenfield P et al. (2016) Genomic insights into the carbohydrate catabolism of Cairneyella variabilis gen. nov. sp. nov., the first reports from a genome of an ericoid mycorrhizal fungus from the southern hemisphere. Mycorrhiza 26:345-352

Midgley DJ, Greenfield P, Bissett A, Tran-Dinh N (2017) First evidence of Pezoloma ericae in Australia: using the Biomes of Australia Soil Environments (BASE) to explore the Australian phylogeography of known ericoid mycorrhizal and rootassociated fungi. Mycorrhiza 27:587-594

Midgley DJ, Sutcliffe B, Greenfield P, Tran-Dinh N (2018) Gamarada debralockiae gen. nov. sp. nov.-the genome of the most widespread Australian ericoid mycorrhizal fungus. Mycorrhiza 28:379-389 
Molina R, Palmer JG (1982) Isolation, maintenance, and pure culture manipulation of ectomycorrhizal fungi. In: Schenck NC (ed) Methods and principles of mycorrhizal research. American Phytopathology Society, St. Paul, pp 115-129

Monreal M, Berch SM, Berbee M (1999) Molecular diversity of ericoid mycorrhizal fungi. Can J Bot 77:1580-1594

Newell SY, Fell JW (1982) Surface sterilization and the active mycoflora of leaves of a seagrass. Bot Mar 25:339-346

Nilsson RH, Ryberg M, Kristiansson E et al. (2006) Taxonomic reliability of DNA sequences in public sequence databases: a fungal perspective. PLoS ONE 1:e59

Nilsson RH, Tedersoo L, Abarenkov K et al. (2012) Five simple guidelines for establishing basic authenticity and reliability of newly generated fungal ITS sequences. MycoKeys 4:37-63

Nichols RV, Vollmers C, Newsom LA et al. (2018) Minimizing polymerase biases in metabarcoding. Mol Ecol Resour 18:927-939

Obase K, Matsuda Y, Ito S (2013) Enkianthus campanulatus (Ericaceae) is commonly associated with arbuscular mycorrhizal fungi. Mycorrhiza 23:199-208

Obase K, Matsuda Y (2014) Culturable fungal endophytes in roots of Enkianthus campanulatus (Ericaceae). Mycorrhiza 24:635-644

Okuda A, Yamato M, Iwase K (2011) The mycorrhiza of Schizocodon soldanelloides var. magnus (Diapensiaceae) is regarded as ericoid mycorrhiza from its structure and fungal identities. Mycoscience 52:425-430

Pearson V, Read D (1973a) Biology of mycorrhiza in the Ericaceae II: transport of carbon and phosphorus by endophyte and mycorrhiza. New Phytol 72:1325-1331

Pearson V, Read DJ (1973b) Biology of mycorrhiza in Ericaceae I: Isolation of endophyte and synthesis of mycorrhizas in aseptic culture. New Phytol 72:371-379

Perotto S, Nepote-Fus P, Saletta L, Bandi C, Young JPW (2000) A diverse population of introns in the nuclear ribosomal genes of ericoid mycorrhizal fungi includes elements with sequence similarity to endonuclease-coding genes. Mol Biol Evol $17: 44-59$

Perotto S, Girlanda M, Martino E (2002) Ericoid mycorrhizal fungi: some new perspectives on old acquaintances. Plant Soil 244:41-53

Peterson RL, Chakravarty P (1991) Techniques in synthesizing ectomycorrhiza. In: Norris JR, Read DJ, Varma AK (eds) Techniques for the study of mycorrhiza. Method Microbiol 23:75-106

Peterson RL, Massicotte HB (2004) Exploring structural definitions of mycorrhizas, with emphasis on nutrient-exchange interfaces. Can J Bot 82:1074-1088

Peterson RL, Massicotte HB, Melville LH (2004) Mycorrhizas: anatomy and cell biology. NRC Research Press, Ottawa

Peterson RL, Wagg C, Pautler M (2008) Associations between microfungal endophytes and roots: do structural features indicate function? Botany 86:445-456

Phillips JM, Hayman DS (1970) Improved procedures for clearing roots and staining parasitic and vesicular-arbuscular mycorrhizal fungi for rapid assessment of infection. Trans Br Mycol Soc 55:158-161

Porras-Alfaro A, Liu K-L, Kuske CR, Xie G (2014) From genus to phylum: large-subunit and internal transcribed spacer rRNA operon regions show similar classification accuracies influenced by database composition. Appl Environ Microb 80:829-840

Rains KC, Nadkarni NM, Bledsoe CS (2003) Epiphytic and terrestrial mycorrhizas in a lower montane Costa Rican cloud forest. Mycorrhiza 13:257-264

Rajendren RB (1972) Evolution of haustoria in tropical rust fungi. Bull Torrey Bot Club 99:84-88
Rice AV, Currah RS (2006) Oidiodendron maius: saprobe in Sphagnum peat, mutualist in ericaceous roots? In: Schulz B, Boyle C, Sieber TN (eds) Microbial root endophytes. Springer Verlag, Berlin Heidelberg, pp 227-246

Read DJ (1983) The biology of mycorrhiza in the Ericales. Can J Bot 61:985-1004

Read DJ (1996) The structure and function of the ericoid mycorrhizal root. Ann Bot 77:365-374

Read DJ, Kerley S (1999) The status and function of ericoid mycorrhizal systems. In: Varma A, Hock B (eds) Mycorrhizastructure, function, molecular biology and biotechnology, 2nd edn. Springer Verlag, Berlin Heidelberg, pp 499-520

Read DJ, Leake JR, Perez-Moreno J (2004) Mycorrhizal fungi as drivers of ecosystem processes in heathland and boreal forest biomes. Can J Bot 82:1243-1263

Repáč I (2011) Ectomycorrhizal inoculum and inoculation techniques. In: Rai M, Varma A (eds) Diversity and biotechnology of ectomycorrhizae. Springer Verlag, Berlin Heidelberg, pp 43-63

Ritz K (2007) The Plate Debate: Cultivable communities have no utility in contemporary environmental microbial ecology. FEMS Microbiol Ecol 60:358-362

Sadowsky JJ, Hanson EJ, Schilder AMC (2012) Root colonization by ericoid mycorrhizae and dark septate endophytes in organic and conventional blueberry fields in Michigan. Int J Fruit Sci 12:169-187

Schild DE, Kennedy A, Stuart MR (1988) Isolation of symbiont and associated fungi from ectomycorrhizas of Sitka spruce. Eur J For Path 18:51-61

Schlegel M, Münsterkötter M, Güldener U et al. (2016) Globally distributed root endophyte Phialocephala subalpina links pathogenic and saprophytic lifestyles. BMC Genomics 17:1015

Schoch CL, Seifert KA, Huhndorf S et al. (2012) Nuclear ribosomal internal transcribed spacer (ITS) region as a universal DNA barcode marker for Fungi. Proc Natl Acad Sci USA 109:6241-6246

Schulz B, Boyle C (2005) The endophytic continuum. Mycol Res 109:661-686

Seifert KA, Rossman AY (2010) How to describe a new fungal species. IMA Fungus 1:109-116

Seifert KA (2017) When should we describe species? IMA Fungus 8:37-39

Selosse M-A, Setaro S, Glatard F et al. (2007) Sebacinales are common mycorrhizal associates of Ericaceae. New Phytol 174:864-887

Selosse MA, Vohník M, Chauvet E (2008) Out of the rivers: are some aquatic hyphomycetes plant endophytes? New Phytol 178:3-7

Setaro S, Weiss M, Oberwinkler F, Kottke I (2006) Sebacinales form ectendomycorrhizas with Cavendishia nobilis, a member of the Andean clade of Ericaceae, in the mountain rain forest of southern Ecuador. New Phytol 169:355-365

Sieber TN (2002) Fungal root endophytes. In: Waisel Y, Eshel A, Kafkafi U (eds) Plant roots - the hidden half, 3rd edn. Marcel Dekker, New York, pp 887-917

Smith JE, Molina R, Perry DA (1995) Occurrence of ectomycorrhizas on ericaceous and coniferous seedlings grown in soils from the Oregon Coast Range. New Phytol 129:73-81

Smith SE, Read DJ (2008a) Ericoid mycorrhizas. In: Smith SE, Read DJ (eds) Mycorrhizal symbiosis, 3rd edn. Academic Press, London, pp 389-418

Smith SE, Read DJ (2008b) The roles of mycorrhizas in the successional processes and in selected biomes. In: Smith SE, Read DJ (eds) Mycorrhizal symbiosis, 3rd edn. Academic Press, London, pp 525-572

Steinke E, Williams PG, Ashford AE (1996) The structure and fungal associates of mycorrhizas in Leucopogon parviflorus (Andr.) Lindl. Ann Bot 77:413-419 
Stevens PF, Luteyn JL, Oliver EGH et al. (2004) Ericaceae. In: Kubitzki K (ed) The families and genera of vascular plants. Springer, Berlin, pp 145-194

Stribley DP, Read DJ, Hunt R (1975) The biology of mycorrhiza in the Ericaceae V. The effect of mycorrhizal infection, soil type and partial soil-sterilization (by gamma-irradiation) on growth of cranberry (Vaccinium macrocarpon Ait.). New Phytol 75:119-130

Štorchová H, Hrdličková R, Chrtek J et al. (2000) An improved method of DNA isolation from plants collected in the field and conserved in saturated $\mathrm{NaCl} / \mathrm{CTAB}$ solution. Taxon 49:79-84

Stroheker S, Queloz V, Sieber TN (2016) Spatial and temporal dynamics in the Phialocephala fortinii s. 1. - Acephala applanata species complex (PAC). Plant Soil 407:231-241

Summerbell RC (2005) Root endophyte and mycorrhizosphere fungi of black spruce, Picea mariana, in a boreal forest habitat: influence of site factors on fungal distributions. Stud Mycol 53:121-145

Tedersoo L, Partel K, Jairus T et al. (2009) Ascomycetes associated with ectomycorrhizas: molecular diversity and ecology with particular reference to the Helotiales. Environ Microb 11:3166-3178

Thompson JD, Higgins DG, Gibson TJ (1994) CLUSTAL W: improving the sensitivity of progressive multiple sequence alignment through sequence weighting, position-specific gap penalties and weight matrix choice. Nucleic Acids Res 22:4673-4680

Urcelay C (2002) Co-occurrence of three fungal root symbionts in Gaultheria poeppiggi DC in Central Argentina. Mycorrhiza 12:89-92

Usuki F, Narisawa K (2005) Formation of structures resembling ericoid mycorrhizas by the root endophytic fungus Heteroconium chaetospira within roots of Rhododendron obsutum var. kaempferi. Mycorrhiza 15:61-64

Vierheilig H, Coughlan AP, Wyss U, Piché Y (1998) Ink and vinegar, a simple staining technique for arbuscular-mycorrhizal fungi. Appl Environ Microbiol 64:5004-5007

Vierheilig H, Schweiger P, Brundrett MC (2005) An overview of methods for the detection and observation of arbuscular mycorrhizal fungi in roots. Physiol Plant 125:393-404

Villarreal-Ruiz L, Anderson IC, Alexander IJ (2004) Interaction between an isolate from the Hymenoscyphus ericae aggregate and roots of Pinus and Vaccinium. New Phytol 164:183-192

Vohník M, Lukančič S, Bahor E et al. (2003) Inoculation of Rhododendron cv. Belle-Heller with two strains of Phialocephala fortinii in two different substrates. Folia Geobot 38:191-200

Vohník M, Albrechtová J, Vosátka M (2005) The inoculation with Oidiodendron maius and Phialocephala fortinii alters phosphorus and nitrogen uptake, foliar $\mathrm{C}$ : $\mathrm{N}$ ratio and root biomass distribution in Rhododendron cv. Azurro Symbiosis 40:87-96

Vohník M, Fendrych M, Albrechtová J, Vosátka M (2007) Intracellular colonization of Rhododendron and Vaccinium roots by Cenococcum geophilum, Geomyces pannorum and Meliniomyces variabilis. Folia Microbiol 52:407-414

Vohník M, Albrechtová J (2011) The co-occurrence and morphological continuum between ericoid mycorrhiza and dark septate endophytes in roots of six European Rhododendron species. Folia Geobot 46:373-386

Vohník M, Sadowsky JJ, Kohout P et al. (2012a) Novel root-fungus symbiosis in Ericaceae: sheathed ericoid mycorrhiza formed by a hitherto undescribed basidiomycete with affinities to Trechisporales. PLoS ONE 7:e39524

Vohník M, Sadowsky JJ, Lukešová T, Albrechtová J, Vosátka M (2012b) Inoculation with wood decomposing basidiomycete, but not with root symbiotic ascomycetes, positively affects growth of highbush blueberry (Ericaceae) grown in a pine litter substrate. Plant Soil 355:341-352
Vohník M, Mrnka L, Lukešová T et al. (2013) The cultivable endophytic community of Norway spruce ectomycorrhizas from microhabitats lacking ericaceous hosts is dominated by ericoid mycorrhizal Meliniomyces variabilis. Fungal Ecol 6:281-292

Vohník M, Borovec O, Župan I et al. (2015) Anatomically and morphologically unique dark septate endophytic association in the roots of the Mediterranean endemic seagrass Posidonia oceanica. Mycorrhiza 25:663-672

Vohník M, Pánek M, Fehrer J, Selosse M-A (2016a) Experimental evidence of ericoid mycorrhizal potential within Serendipitaceae (Sebacinales). Mycorrhiza 26:831-846

Vohník M, Borovec O, Kolařík M (2016b) Communities of cultivable root mycobionts of the seagrass Posidonia oceanica in the northwest Mediterranean Sea are dominated by a hitherto undescribed pleosporalean dark septate endophyte. Microb Ecol $71: 442-451$

Vohník M, Borovec O, Župan I, Kolařík M, Sudová R (2017) Fungal root symbionts of the seagrass Posidonia oceanica in the central Adriatic Sea revealed by microscopy, culturing and 454-pyrosequencing. Mar Ecol Prog Ser 583:107-120

Vohník M, Borovec O, Kolaříková Z, Sudová R, Réblová M (2019) Extensive sampling and high-throughput sequencing reveal Posidoniomyces atricolor gen. et sp. nov. (Aigialaceae, Pleosporales) as the dominant root mycobiont of the dominant Mediterranean seagrass Posidonia oceanica. MycoKeys 55:59-86

Vrålstad T, Fossheim T, Schumacher T (2000) Piceirhiza bicolorata - the ectomycorrhizal expression of the Hymenoscyphus ericae aggregate? New Phytol 145:549-563

Vrålstad T, Myhre E, Schumacher T (2002) Molecular diversity and phylogenetic affinities of symbiotic root-associated ascomycetes of the Helotiales in burnt and metal polluted habitats. New Phytol 155:131-148

Vrålstad T (2004) Are ericoid and ectomycorrhizal fungi part of a common guild? New Phytol 164:7-10

Vu D, Groenewald M, de Vries M et al. (2019) Large-scale generation and analysis of filamentous fungal DNA barcodes boosts coverage for kingdom fungi and reveals thresholds for fungal species and higher taxon delimitation. Stud Mycol 92:135-154

Walker JF, Aldrich-Wolfe L, Riffel A et al. (2011) Diverse Helotiales associated with the roots of three species of Arctic Ericaceae provide no evidence for host specificity. New Phytol 191:515-527

Wilson D (1995) Endophyte: the evolution of a term, and clarification of its use and definition. Oikos 73:274-276

Xiao G, Berch M (1996) Diversity and abundance of ericoid mycorrhizal fungi of Gaultheria shallon on forest clearcuts. Can J Bot 74:337-346

Xu L, Li S, Shabala S, Jian T, Zhang W (2019) Plants grown in Parafilm-wrapped Petri dishes are stressed and possess altered gene expression profile. Front Plant Sci 10:637

Zamora JC, Svensson M, Kirschner R et al. (2018) Considerations and consequences of allowing DNA sequence data as types of fungal taxa. IMA Fungus 9:167-175

Zhang C, Yin LJ, Dai SL (2009) Diversity of root-associated fungal endophytes in Rhododendron fortunei in subtropical forests of China. Mycorrhiza 19:417-423

Baba T, Hirose D (2020) Morphological characteristics of rhizodermal colonization by Leohumicola species in an ericaceous host. Plant Root 14:1-10

Publisher's Note Springer Nature remains neutral with regard to jurisdictional claims in published maps and institutional affiliations. 